$\mathcal{G S}_{\text {http://dx.doi.org/10.3765/sp.8.8 }}^{\text {Semantics \& Pragmatics Volume 8, Article 8: 1-38, } 2015}$

\title{
The ingredients of comparison: The semantics of the excessive construction in Japanese*
}

\author{
Xiao Li \\ Queens College, CUNY
}

Submitted 2014-01-03 / First decision 2014-03-04 / Revision received 2014-05-20 / Second decision 2014-06-04 / Revision received 2014-06-16 / Accepted 2014-06-19 / Published 2015-05-13

\begin{abstract}
Excessives (e.g., this pair of pants is too long) are often considered as a 'degree construction' in the literature, presumably because it is assumed that their semantics involves a comparison of degrees. This paper takes a cross-linguistic look at the excessive construction in Japanese and raises the question of whether degrees are a necessary ingredient in the semantics of comparison. Unlike any degree morpheme in English, -sugi 'to exceed' can combine with either a gradable adjective (e.g., naga 'long') or a non-gradable verb (e.g., yomi 'to read') to form an excessive construction. In each case, a semantically different type of phrase can be used as a differential: when -sugi combines with an adjective, a measure phrase can be used as a differential; when -sugi combines with a verb, a floating numeral quantifier can be used as a differential. Based on this observation, I put forward a non-degree based analysis in which -sugi is not a degree quantifier. Specifically, I argue that a V-sugi sentence describes a comparison of two sets of objects or events, whereas an Adj-sugi sentence describes a comparison of two sets of degrees. This analysis draws an interesting parallel to the A-not-A analysis of the comparative in the literature, and implies that the semantics of a 'degree construction' does not necessarily involve a comparison of degrees.
\end{abstract}

Keywords: excessives, comparison, degrees, the A-not-A analysis, Japanese

* This paper benefited from discussions with and comments from Mark Baker, Adrian Brasoveanu, Carlos A. Fasola, Chris Kennedy, Mana Kobuchi-Philip, William McClure, Maribel Romero, Roger Schwarzschild, Chung-chieh Shan, Satoshi Tomioka, and the audience at the $18^{\text {th }}$ Japanese/Korean Linguistics Conference. In particular, I am indebted to Roger Schwarzschild, Carlos A. Fasola and Mana Kobuchi-Philip for detailed written comments on various versions of the paper. I am very grateful to the editor, David Beaver, and three anonymous S\&P reviewers for constructive comments, which led to substantial improvement. I thank my Japanese informants: Ken Hiraiwa, Koichi Nishitani, Koji Kawahara, Sachie Kotani, Shigeto Kawahara, Mai Kumagami, Mari Fujimoto, Miho Nagai, and Tomoyuki Yabe for their judgments and the discussions about the data. All remaining mistakes are my own.

(C) 2015 Xiao Li

This is an open-access article distributed under the terms of a Creative Commons Attribution License (http://creativecommons.org/licenses/by/3.o/). 


\section{Introduction}

The excessive construction in English, exemplified in (1), has been traditionally analyzed as a degree construction which involves a comparison of an actual degree and a modalized one (von Stechow 1984, Heim 2000, Meier 2003). For instance, the sentence in (1) describes a comparison between the degree to which this pair of pants is long and the degree to which it would have been long if it had met the requirement (e.g., this pair of pants is required to be exactly 34 inches long, but it is actually 36 inches long). The measure phrase two inches in (1) is a differential, which describes the difference between two degrees under comparison. ${ }^{1}$

(1) This pair of pants is two inches too long.

In Japanese, the excessive construction is expressed through the morpheme -sugi 'to exceed', which can be attached to an adjective or a verb to add an excessive meaning. For instance, the Japanese equivalent of (1) is in (2), where -sugi is attached to the adjective naga 'long' to form an excessive construction.

(2) Kono pantsu-ga ni inchi naga-sugi-ru.

this pant-NOM 2 inch long-exceed-present

'This pair of pants is two inches too long.'

Interestingly, -sugi combines not only with gradable adjectives but also with verbs. In the latter case, a floating numeral quantifier (FNQ) can be used as a differential, as shown in (3).

(3) John-ga hon-o kinoo san-satu yomi-sugi-ta.

John-NOM book-ACC yesterday 3-Cl[assifier] read-exceed-PAST

'Yesterday John read three books too many.'

(Nakanishi 2007a: 172)

In (3), san-satu ' 3 -Cl' is a floating numeral quantifier, which is separated from its host noun hon 'book' by the adverb kinoo 'yesterday.' The sentence means: compared to what should have been read, John read three books too

1 A differential is a phrase that describes the difference between two items under comparison. For example, in the English comparative John is two inches taller than Mary, the measure phrase two inches is a differential that describes the difference between John's height and Mary's height. 
many (i.e., John is required to read no more than three books, but he read six). The FNQ san-satu in (3) is a differential, which describes the difference between what John actually read and what he would have read, had he met the requirement.

Floating numeral quantifiers and measure phrases are semantically different types of phrases: the former have a quantificational reading; they are known for the distributive reading that they associate a sentence with (Terada 1990, Kitagawa \& Kuroda 1992, Kato 1997, Sasaki Alam 1997, Ishii 1998, Nakanishi 2004b, 2007a,b, Kobuchi-Philip 2003, 2007). Compare (4a) with (4b).

(4) a. [Gakusei san-nin $]_{N p}$-ga sono mise-de terebi-o katta. students 3-Cl-NOM the store-at tv-ACC buy-PAST

'Three students bought a TV set at the store.'

b. Gakusei-ga sono mise-de, san-nin terebi-o katta. student-NOM the store-at 3 -Cl tv-ACC buy-PAST

'Three students (each) bought a TV set at the store.'

In (4a), the NP gakusei 'student' forms a constituent with san-nin, which is case-marked by -ga. In (4b), san-nin is a FNQ, which is separated from the host NP gakusei 'students' by the postpositional phrase sono mise-de 'at the store'. (4a) can be true in at least three situations: (i) three students together bought a TV set; (ii) some of the students each bought a TV set while others bought a TV set together; (iii) each of the three students bought a TV set. (4b) is true only in the situation where three students each bought a TV set.

Measure phrases, on the other hand, are often analyzed as names of degrees (of type $\langle d\rangle$ ) (von Stechow 1984). For example, the measure phrase 2 inches in (1) denotes a degree on a scale of length. In light of the semantic difference between measure phrases and FNQs, this paper aims to address the following question: what is it about the meaning of -sugi such that it is compatible with both gradable adjectives (e.g., naga 'long') and non-gradable verbs (e.g., yomi 'to read'), and allows both degree-denoting (e.g., ni inchi '2 inches') and non-degree denoting differentials (e.g., san-satu ' 3 -Cl')?

In the paper, I provide a unified interpretation of -sugi which maintains the semantic difference between FNQs and measure phrases. I argue that -sugi, unlike too in English, is not a degree quantifier. When -sugi combines with a gradable adjective like in (2), the sentence describes a comparison of two (sets of) degrees. A measure phrase can serve as a differential to describe the difference between two degrees. When -sugi combines with a 
non-gradable verb like in (3), the sentence describes a comparison of two sets of individuals, one being a proper superset of the other. A FNQ can serve as a differential that quantifies over the difference between the two sets. I show that such an analysis draws an interesting parallel to the A-not-A analysis of comparatives in the literature (Ross 1969, Seuren 1973, 1984, McConnell-Ginet 1973, Schwarzschild 2008), and implies that degrees are not a necessary ingredient in the semantics of comparison.

This paper is structured as follows. Section 2 provides a brief review of Nakanishi (2004a, 2004b, 2007a)'s analysis of -sugi, where the limitations of her analysis are discussed. Section 3 outlines an alternative non-degree based analysis of -sugi, where I argue that the -sugi construction in Japanese, unlike the too construction in English, compares not only two sets of degrees, but also two sets of individuals and events. In Section 4, I compare the analysis of -sugi to the A-not-A analysis of the comparative in the literature, and show that the latter, which is proposed to account for the adjectival comparative in English (e.g., John is taller than Mary is), is compatible with comparison constructions that do not necessarily involve comparisons of degrees. Section 5 concludes the paper. The Appendix addresses two additional issues: the non-salient reading of (3) - 'John over-read the three books' - and the subject-oriented FNQ in the -sugi construction. ${ }^{2}$

\section{A degree-based approach to -sugi}

The most detailed semantic analysis of -sugi in the literature is due to Nakanishi (2004a, 2004b, 2007a), who argues that -sugi has a meaning similar to too in English. Before considering her analysis, let us first take a look at the meaning of the too construction in (1).

(5) LF of (1): [DegP two inches too $]_{i}\left[\lambda d\right.$. This pair of pants is $d_{i}$-long].

a. $\llbracket$ too $\rrbracket=\lambda d \lambda D_{\langle d, t\rangle} \cdot \max (D)-C=d$

b. $\llbracket(1) \rrbracket=1$ iff $\max \{\lambda d$. This pair of pants is $d$-long $\}-C=2$ inches

The sentence in (1) has the LF in (5), where too is a quantifier that binds the degree argument of the adjective long. Too takes two semantic arguments: a differential degree and a set of degrees to which the subject possesses some

2 FNQs fall into two kinds - subject-oriented FNQs and object-oriented FNQs - depending on whether the NPs they are associated with are subjects or objects. Subject-oriented FNQs are not allowed in the -sugi construction, which we will turn to in the appendix. 
The ingredients of comparison

property. Under this analysis, the sentence in (1) has the truth-conditions in (5b), which says: (1) is true iff the maximal degree to which this pair of pants is long exceeds some contextually supplied standard $C$ by two inches. ${ }^{3}$

In Nakanishi (2004a, 2004b) and Nakanishi (2007a), the meaning of -sugi is essentially modeled after that of too in (5a). An important assumption behind her analysis is that FNQs in the -sugi construction are different from those in non-sugi contexts; the former have the syntax and semantics of measure phrases. She proposes that the -sugi sentence in (3) has the LF in (6):

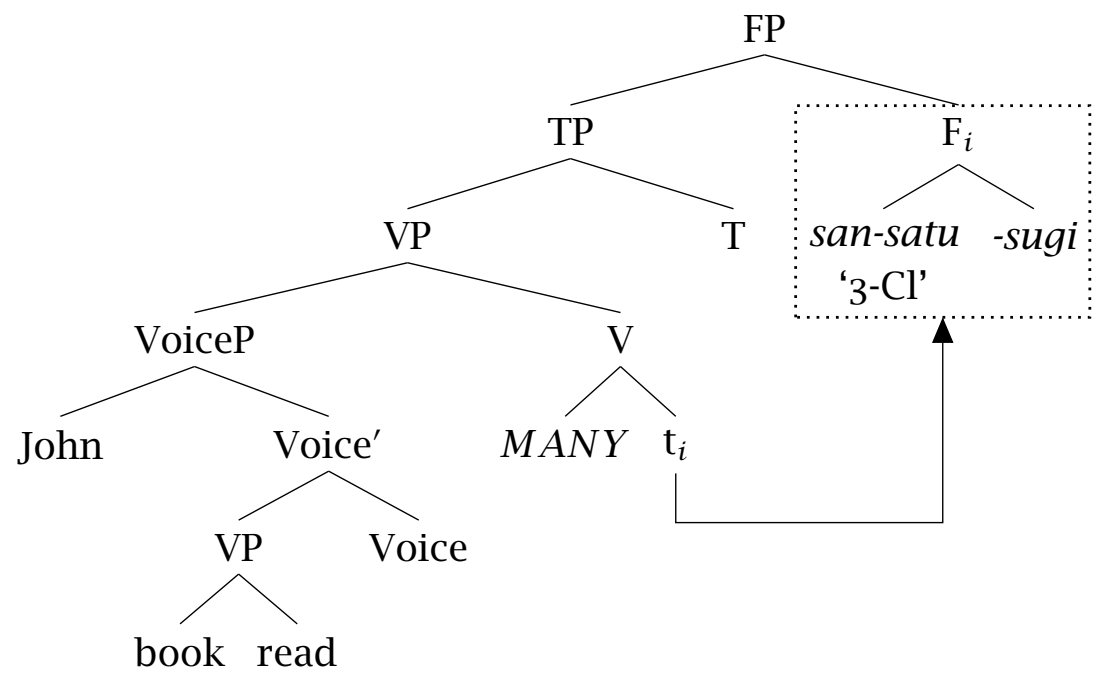

(Nakanishi 2007a: 205)

The structure in (6) is built upon several syntactic and semantic assumptions. First, following Sugioka (1985), Kageyama \& Yumoto (2007), Koizumi (1998), Nakanishi assumes that -sugi, like 'seems' in English, is a raising verb that takes a sentential complement. In (6), this sentential complement is represented by the VoiceP. Second, -sugi is assumed to be a complex head which can be decomposed into two main components: (i) a DegP consisting of a Deg head, -sugi, and an optional differential argument; and (ii) an implicit $M A N Y$. In (6), the differential argument of -sugi is the FNQ san-satu.

Semantically, Nakanishi assumes that verbs take an event argument in addition to other thematic arguments. The VoiceP in (6) denotes a set of events of John reading books, as shown in (7a). The implicit MANY relates

3 The meaning of too in (5) is a much simplified version of the one proposed in Heim (2000) and Meier (2003). $C$ in (5a-b) is a modalized degree, whose value is determined by a counterfactual conditional like the following: "if this pair of pants had met the requirement, it would have been $C$-long”. 
the set of events denoted by the VoiceP to a degree, $d$. In (7b), $h$ and $\mu$ are contextually supplied variables: $h$ is a homomorphism which can map from an event to its temporal trace, spatial extent or patients; $\mu$ is a measure function that measures cardinality or temporal/spatial length. In (6), $h$ maps from the event of John reading books to the set of books that John read in the event; $\mu$ measures the cardinality of the set. -sugi has the same semantics as too; it compares two degrees: the degree $d$ resulted from applying the denotation of MANY to the set of events denoted by the VoiceP, and a contextually supplied standard $C$. The difference between the two degrees is expressed by the FNQ san-satu, which has the semantics of a measure phrase, as shown in $(7 \mathrm{~d})$.

$$
\begin{aligned}
& \text { a. } \llbracket \text { VoiceP } \rrbracket=\lambda e_{v} \cdot \exists x_{e}\left[\operatorname{Agent}(e)=j \wedge^{*} \operatorname{book}(x) \wedge^{*} \operatorname{read}(x, e)\right] \\
& \text { b. } \llbracket M A N Y \rrbracket=\lambda d_{d} \lambda P_{\langle v, t\rangle} \cdot \exists e_{v}[P(e) \wedge \mu(h(e))=d] \\
& \text { c. } \llbracket \text {-sugi } \rrbracket=\lambda d \lambda D_{\langle d, t\rangle} \cdot \max (D)-C=d \\
& \text { d. } \llbracket \text { san-satu } \rrbracket=3 \\
& \text { e. } \llbracket(3) \rrbracket=1 \text { iff } \max \{d: \exists e \exists x[\operatorname{Agent}(e)= \\
& \left.\left.\qquad j \wedge^{*} \operatorname{book}(x) \wedge^{*} \operatorname{read}(x, e) \wedge \mu(h(e))=d\right]\right\}-C=3
\end{aligned}
$$

Under this analysis, sentence (3) has the truth-conditions in (7e), which says: the maximal number of books that John read exceeds the contextual standard C by 3 .

Nakanishi's analysis provides an accurate picture of what it is like for -sugi to be interpreted as a degree quantifier like too in English. However, her assumption that FNQs in -sugi and non-sugi sentences are different is worth further investigation. ${ }^{4}$ Evidence from the distribution of FNQs in -sugi and non-sugi contexts suggests that they may not be different.

4 Nakanishi (2004b, 2007a) observes that subject-oriented FNQs are not allowed in the -sugi construction, as shown in (i). Based on this observation, she argues that FNQs in the -sugi construction are different from those in non-sugi contexts. In the appendix, I show that examples like (i) do not constitute conclusive evidence for her claim.

(i) a. Gakusei-ga kinoo san-nin sono miitingu-ni sankasi-ta. student-NOM yesterday 3 -Cl that meeting-in participate-PAST

'Three students participated in that meeting yesterday.'

b. ??Gakusei-ga kinoo san-nin sono miitingu-ni sankasi-sugi-ta student-NOM yesterday 3 - $\mathrm{Cl}$ that meeting-in participate-exceed-pst Intended: three students too many participated in the meeting yesterday. 
The ingredients of comparison

a. John-ga gakusei-ni kinoo futa-ri hon-o watasi-ta. John-NOM student-DAT yesterday 2-Cl book-ACC hand-PAST

'John gave two students books yesterday.'

b. *John-ga gakusei-ni hon-o futa-ri watasi-ta. John-NOM student-DAT book-ACC 2-Cl hand-PAST

(9) a. John-ga gakusei-ni kinoo futa-ri hon-o

John-NOM student-DAT yesterday 2-Cl book-ACC

watasi-sugi-ta.

hand-exceed-PAST

'John gave books to two students too many yesterday.'

b. ??John-ga gakusei-ni hon-o futa-ri watasi-sugi-ta. John-NOM mstudent-DAT book-ACC 2-Cl hand-exceed-PAST

The contrast in (8) shows that it is not possible to float a numeral quantifier of a dative case-marked object across an accusative-case marked object. The contrast in (9) shows that the same pattern holds for the -sugi construction.

(10) *hikooki-ga hikoojoo-kara, yon-kasho tobitatta airplane-NOM airport-from 4-Cl departed Intended: 'Airplanes departed from four airports.'

(11) *hikooki-ga hikoojoo-kara, yon-kasho tobitat-sugi-ta airplane-NOM airport-from 4-Cl depart-exceed-PAST

Intended: 'Airplanes departed from four airports too many.'

(10) and (11) are another pair of examples that demonstrate the parallel between FNQs in -sugi and non-sugi contexts. (10) shows that floating the numeral classifier of a NP object outside of a postpositional phrase results in the ungrammaticality of a sentence; (11) shows that adding -sugi does not reverse this result.

The examples in (8-11) together indicate that FNQs in -sugi sentences are subject to the same distributional restrictions as those in non-sugi contexts. If the former are the same as the latter, we can let the ungrammaticality of the -sugi sentences in (9b) and (11) follow from the same source of explanation that accounts for the ungrammaticality of the non-sugi sentences in (8b) and (10). Everything else being equal, an analysis of -sugi that maintains the syntax and semantics of FNQs in -sugi and non-sugi-sentences is more economical and satisfactory than one that assumes otherwise. 
Another issue with Nakanishi's analysis concerns the use of the homomorphism, $h$, which maps from an event to its temporal trace, spatial extent or patients (e.g., in (7e) $h$ maps the reading events to the books being read in the events). Such flexibility brings with it a potential of overgeneration. It predicts that the sentence in (12) has an unattested reading, 'John read three books, and that was too much.'5 Below I explain why this is so.

(12) John-ga [hon san-satu]-o kinoo yomi-sugi-ta.

John-NOM book 3-Cl-ACC yesterday read-exceed-PAST

'John over-read (the) three books yesterday.'

In (12), san-satu is not a FNQ; rather it is a post-nominal modifier that forms a constituent with the NP hon 'book'. (12) means: 'John over-read the three books yesterday. It is true either in a scenario where John read the three books for too long (e.g., John is required to read the three books for three hours, but he read them for six hours), or in a scenario where he read the three books too many times (e.g., John is required to read the three books three times, but he read them six times).

To see how this reading is compositionally achieved under Nakanishi's analysis, let us consider the LF of (12) in (13).

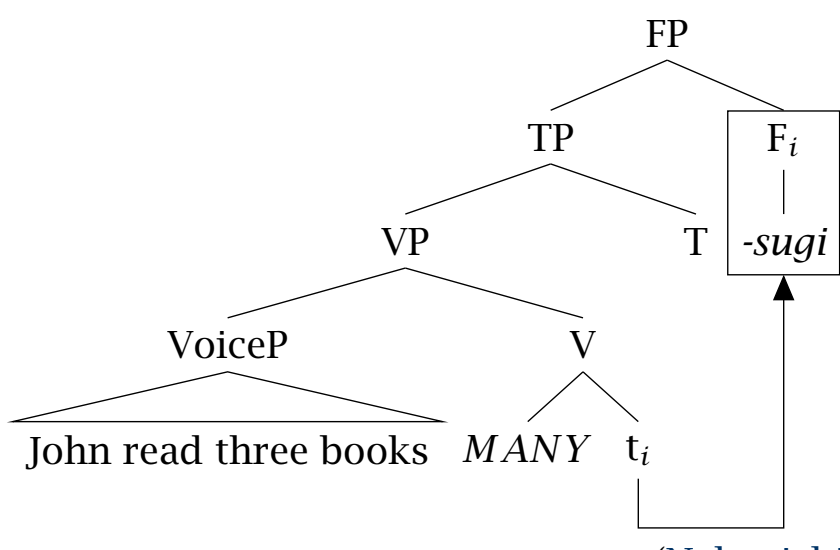

(Nakanishi 2007a: 206)

The structure in (13) mainly differs from that in (6) in the position of san-satu. In (13), san-satu appears in the object position inside the VoiceP. Semantically, the VoiceP denotes a set of events of John reading three books,

5 An anonymous reviewer points out that for some Japanese speakers, (12) can also mean 'John overdid the reading by three books' (e.g., John is required to read exactly three books, but he read six). This reading does not pertain to our discussion here. 
as shown in (14a). MANY relates the set of events to a degree $d$, as shown in (14b). -sugi in (13) does not take a differential argument; it indicates that $d$ is greater than a contextual standard, $C$, as shown in (14c). The truth-conditions of (12) are expressed by the formula in (14d).

(14) a. $\llbracket$ VoiceP $\rrbracket=\lambda e_{v} \cdot \exists x_{e}\left[\operatorname{Agent}(e)=j \wedge * \operatorname{book}(x) \wedge|x|=3 \wedge^{*} \operatorname{read}(x, e)\right]$

b. $\llbracket M A N Y \rrbracket=\lambda d_{d} \lambda P_{\langle v, t\rangle} . \exists e_{v}[P(e) \wedge \mu(h(e))=d]$

c. $\llbracket$-sugi $\rrbracket=\lambda D_{\langle d, t\rangle} \cdot \max (D)>C$

d. $\llbracket(12) \rrbracket=1$ iff $\max \{d: \exists e \exists x[\operatorname{Agent}(e)=$ $\left.\left.j \wedge^{*} \operatorname{book}(x) \wedge|x|=3 \wedge^{*} \operatorname{read}(x, e) \wedge \mu(h(e))=d\right]\right\}>C$

In (14d), the homomorphism $h$ can be a mapping either from events to their temporal trace or from events to their spatial extent. Given that it is absurd to map reading events to spatial extent, $h$ maps from the reading events to their temporal trace. In such a case, (12) receives the reading 'John read the three books for too long.' Additionally, (12) can also mean 'John read the three books too many times.' In this case, $h$ is vacuous, and MANY directly measures the cardinality of the events.

Crucially, as Nakanishi points out, $h$ in (14d) cannot be a mapping from events to their patients. She argues that this is so because the cardinality of books is already specified by the measure phrase san-satu. However, we can be unsatisfied with this explanation, since the reading resulting from letting $h$ map from events to patients is indeed a plausible one. (14d) can be paraphrased as: the maximal number of books John read, which is three, exceeds the contextual standard. In other words, it says: John read three books, and that was too much.

Besides the above mentioned issues, Nakanishi's analysis of -sugi raises a more general question regarding the semantics of the excessive construction. In her analysis, the main function of the implicit predicate $M A N Y$ is to relate VPs that do not contain a degree to a degree. This analysis presupposes that degrees are a necessary ingredient in the semantics of excessives. But is it really so? Or can we develop an alternative analysis of -sugi without $M A N Y$ ? In the following section, I will take up this task and propose a nondegree-based approach to the semantics of -sugi, wherein -sugi is not a degree quantifier. 


\section{A non-degree-based approach to -sugi}

In this section we mainly consider the meaning of -sugi in two situations: when -sugi combines with a non-gradable verb (e.g., yomi 'to read') (Section 3.1), and when -sugi combines with a gradable adjective (e.g., naga 'long') (Section 3.2). I argue that in both cases a -sugi sentence expresses a supersetsubset relation between two sets of objects. Depending on what predicate -sugi combines with, this can be either a superset-subset relation between two sets of individuals/events or one between two sets of degrees.

\subsection{V-sugi}

To begin with, I will lay out the main syntactic assumptions that I adopt for a -sugi sentence like (3). First, following Fukushima (1991), Fujita (1994), Kobuchi-Philip (2003, 2007), I assume that object-oriented FNQs such as san-satu in (15) are base-generated VP adverbs.

(15) John-ga hon-o san-satu yonda.

John-NOM book-ACC 3-Cl read-PAST

'John read three books.'

The adverbial analysis of the FNQ is supported by the examples in (16), where the object-oriented FNQs, san bai and go mai, can be conjoined with the VP-adverbs, kireini 'cleanly' and sude-de 'with bare hands', respectively. ${ }^{6}$

(16) a. Mary-ga raamen-o, san-bai katsu kireini tairageta. Mary-NOM soup-ACC 3 - $\mathrm{Cl}$ and cleanly ate up 'Mary ate up three bowls of soup noodles completely.'

b. John-ga ita-o, go-mai katsu sude-de watta. John-NOM plank-ACC 5-Cl and bare hand-with split 'John split five planks bare handedly just now.'

(Kobuchi-Philip 2003: 79)

6 See Kobuchi-Philip (2003) for other evidence in support of the adverbial analysis of FNQs. 
The ingredients of comparison

It has also been argued that FNQs must be c-commanded by their host NPs (Miyagawa 1989, Doetjes 1997). ${ }^{7}$ Kobuchi-Philip (2003, 2007) proposes the following configuration for object-oriented FNQs, as shown in (17).

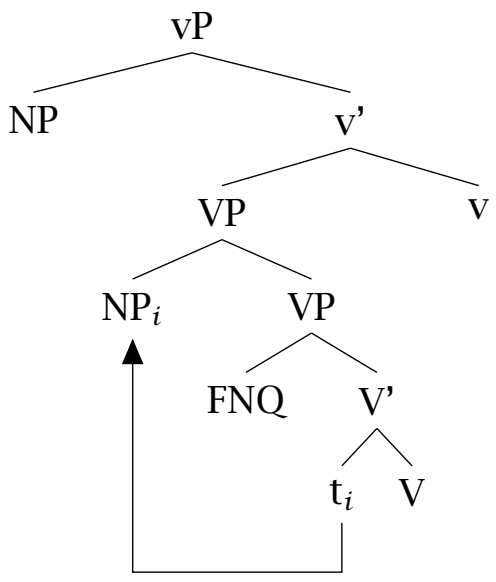

In (17), the object-oriented FNQ is a base generated adverb. The object NP is moved from its theta-position to c-command the FNQ. It follows that the sentence in (15) has the structure in (18), where the object-oriented FNQ san-satu is a VP-adverb, and its host NP hon 'book' moves from the object position of the verb yomi 'read' to c-command it.

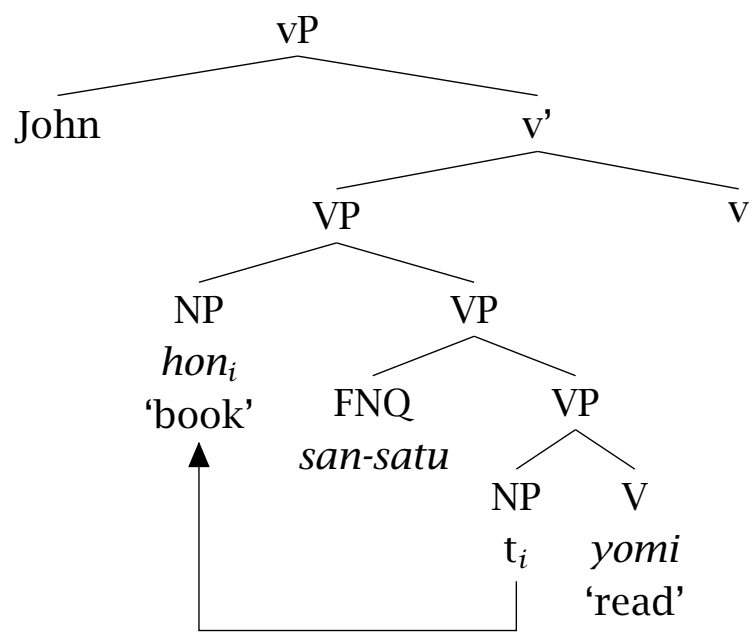

7 See Miyagawa (1989) for the mutual c-command constraint on the FNQ in Japanese. In (17), this constraint is satisfied by the c-commanding relation between the moved host NP and the FNQ, and the c-commanding relation between the FNQ and the trace left by the NP movement. Doetjes (1997) provides evidence from German and French in support of the c-commanding relation between the host NP and the FNQ. 
In addition, I assume that -sugi is a raising verb that takes a sentential complement (Sugioka 1985, Kageyama \& Yumoto 2007, Koizumi 1998). Koizumi (1998) observes that a raising verb and a control verb in Japanese may have different scopes with respect to their objects. A sentence with a raising verb may have a wide scope and a narrow scope reading, as shown in (19a); but a sentence with a control verb only has a wide scope reading, as shown in (19b).

(19) a. John-wa ringo-dake-o tabe-hazime-ta. John-TOP apple-only-ACC eat-start-PAST

i. only > start (it is only apples that John started to eat)

ii. start $>$ only (it is eat only apples that John started to do)

b. John-wa ringo-dake-o tabe-wasure-ta. John-TOP apple-only-ACC eat-forget-PAST

i. only $>$ forget (Among many things John was supposed to eat, it is only apples that he forgot to eat.)

ii. *forget > only

(Koizumi 1998: 5)

Given the contrast above, -sugi is shown to be a raising verb. When it combines with the verb tabe 'to eat', the sentence is ambiguous between two readings, as shown in (20).

(20) John-wa niku-dake-o tabe-sugi-ta.

John-TOP meat-only-Acc eat-exceed-PAST

i. only > sugi (Among many things John ate, it is only meat that he overate)

ii. sugi $>$ only (For too long a time, John ate nothing but meat)

(Koizumi 1998: 5)

It follows that a -sugi sentence has the structure in (21), where -sugi takes a sentential complement to form a VP. The subject of the vP is raised to the spec of the TP to receive nominative case (Sugioka 1985, Kageyama \& Yumoto 2007, Koizumi 1998): 
The ingredients of comparison

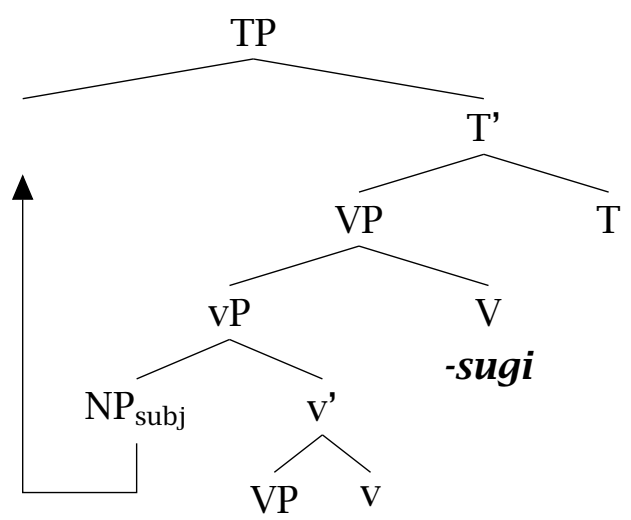

The two syntactic assumptions above, namely (i) object-oriented FNQs are VP adverbs and (ii) -sugi is a raising verb that takes a vP complement, predict that the sentence in (3) (repeated below) has the syntactic structure in (22): ${ }^{8}$

(3) John-ga hon-o kinoo san-satu yomi-sugi-ta John-NOM book-ACC yesterday 3-Cl read-exceed-PAST

'John read three books too many yesterday.'

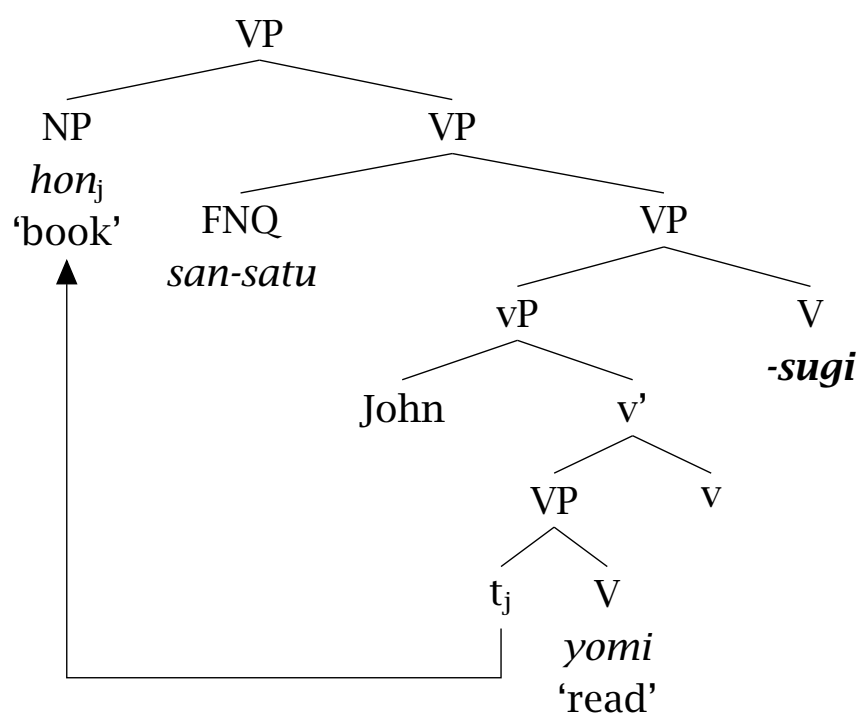

In (22), -sugi takes a vP complement and forms a VP. The FNQ san-satu is a VP adverb, and is adjoined to the VP above -sugi. The host NP hon 'book'

8 The two syntactic assumptions also predict that (3) has another syntactic structure where the FNQ san-satu is attached to the VP inside the vP. In the appendix, I show that this structure is associated with a less salient reading - 'John over-read the three books' (e.g., John is required to read the three books for two hours, but he read them for six hours). 
is moved to adjoin to the VP to c-command the FNQ san-satu (cf. (17)). To achieve the right surface order, the subject John is raised to the specifier position of the TP to receive nominative case.

Having clarified the syntactic structure of (3), we now proceed to interpret it. Intuitively, a -sugi sentence implies that there is an amount requirement in the context that sets an upper bound on admissible values and that this requirement is violated. Compare the two scenarios in (23) and (24) below, and consider the truth-value of (3) in them.

(23) Scenario: In the final exam of an intensive reading class, the professor selected five English books, \{A, B, C, D, E\}, and required each student to read exactly (or at most) two books from the set. This way, each of them would have some fresh material that he had not yet seen in the exam. John read all the five books.

(24) Scenario: In the final exam of an intensive reading class, the professor selected five English books, $\{\mathrm{A}, \mathrm{B}, \mathrm{C}, \mathrm{D}, \mathrm{E}\}$, and required each student to read at least two books from the set. John read all the five books.

(23) differs from (24) in the amount requirement. The former specifies the maximal amount of books that one is allowed to read. John violated this requirement by reading more than allowed. The latter, on the other hand, specifies the minimal amount of books that one is required to read. John read more than minimally required, but unlike in (23), he did not violate the reading requirement. Intuitively, (3) is true in (23), but false in (24).

Given the comparison above, we can paraphrase (3) by a counterfactual conditional like the one in (25).9

(25) If the reading requirement had been met, John would have read three books less.

(25) compares two sets of objects: the set of books John read and the set of books John would have read, had he met the reading requirement. Under Stalnaker (1968)'s analysis of counterfactual conditionals, this can be

9 The idea that conditionals play a role in the semantics of excessives is attributed to Meier (2003). She argues that in the excessive construction such as 'the food is too good to (be allowed to) throw (it) away,' the sentential complement - 'to throw it away' expresses an incomplete conditional - 'if the food is d-good, we are allowed to throw it away.' The -sugi construction in Japanese differs from the too-construction in not containing such a sentential complement. However, given the discussion on the scenarios in (23-24) above, (3) can be interpreted as 'John read three books too many to meet the reading requirement.' 
translated into a comparison between the set of books that John read in the evaluation world, $w$, and the set of books that John read in the closest possible world, $w^{\prime}$, to $w$, where the reading requirement is met. The notion 'closest' is defined in terms of similarity. The closest possible world, $w$ ', to $w$, where the relevant requirement is met is the world which is most similar to $w$ where the relevant requirement is met. In the formal analysis, $w^{\prime}$ is derived by applying a contextually supplied selection function, $f$, to an antecedent, $P$, and an evaluation world, $w$, that is, $f(p, w)=w^{\prime}$.

To illustrate how this analysis works to capture the truth-values of (25), let us consider it in the scenario in (26). (26) differs from (23) in that its reading requirement is to read 'exactly' two books.

(26) Scenario: In the final exam of an intensive reading class, the professor selected five English books, \{A, B, C, D, E\}, and required each student to read exactly two books from the set. This way, each of them would have some fresh material that he had not yet seen in the exam. John violated this requirement by reading all the five books.

In (26), there are two sets of objects under comparison: the set of books John read in the evaluation world, $w$, and the set of books John read in the closest possible world, $w^{\prime}$, to $w$, where the reading requirement is met. The former is $\{A, B, C, D, E\}$. The latter is decided by which world we consider as the closest possible world, $w^{\prime}$, to $w$, where the reading requirement is met. Given the situation in (26), $w^{\prime}$ can be any world where John read exactly two of the five books. There are ten such worlds, i.e., $w_{1}^{\prime}$ where John read $\{\mathrm{A}, \mathrm{B}\}$, $w_{2}^{\prime}$ where John read $\{\mathrm{A}, \mathrm{C}\}, w_{3}^{\prime}$ where John read $\{\mathrm{A}, \mathrm{D}\}, w_{4}^{\prime}$ where John read $\{\mathrm{A}$, $E\}$, etc. ${ }^{10}$ Here we run into a problem. Stalnaker's analysis of counterfactual conditionals assumes that for any possible world $w$ and antecedent $P$, there is a unique closest possible world, $w^{\prime}$, to $w$, where $P$ is true (also known as the Uniqueness Assumption). However, situations like (26) suggest that this assumption cannot always be met.

One way to solve this problem, as argued in Stalnaker (1984), is to resort to supervaluations (Fraassen 1969). That is, for each one of the worlds that are closest to the evaluation world where the antecedent is true, there is a distinct selection function that selects for it. In (26), there are ten such selection functions, each of which corresponds to a unique closest antecedent-world. A counterfactual conditional is supertrue iff the consequent is true in all the

10 I assume a framework of possible world semantics in which entities (i.e., individuals, events and degrees) have transworld identity, i.e., they may exist in more than one possible world. 
closest antecedent-worlds; it is superfalse iff the consequent is false in all the closest antecedent-worlds; it is neither true nor false iff the consequent is true in some of the closest antecedent-worlds, but false in others. It follows that the counterfactual conditional in (25) is supertrue in (26), because no matter which selection function that the context picks, the difference between the set of objects that John read in the evaluation world, namely $\{\mathrm{A}, \mathrm{B}, \mathrm{C}$, $\mathrm{D}, \mathrm{E}\}$, and the set of books John read in a closest possible world, $w^{\prime}$, to $w$, where the reading requirement is met, namely, $\{\mathrm{A}, \mathrm{B}\},\{\mathrm{A}, \mathrm{C}\},\{\mathrm{A}, \mathrm{D}\}$, etc., is three books. ${ }^{11,12}$

To keep the analysis simple, I will ignore violations of the uniqueness assumption (e.g., (26)) and its treatment (i.e., supervaluations), and assume from now that for any possible world $w$ and requirement $r$, there is a unique closest requirement-compatible world $\mathrm{w}_{r}$. Given the structure in (22), I propose that sugi has the meaning in (27), with $\mathrm{w}_{r}$ and $\bigsqcup_{P}$ defined in (28).

$$
\llbracket \text { sugi }_{r} \rrbracket^{g}=\lambda w_{s} \lambda P_{\langle s,\langle\tau, t\rangle\rangle} \lambda x_{\tau}\left[P(w)(x) \wedge \neg P\left(w_{r}\right)(x) \wedge w_{r} \sqsubseteq_{P} w\right]
$$

(28) a. $w_{r}$ is the closest possible world to $w$ where the requirement $r$ is met, that is, $w_{r} \equiv f(r, w)$.

b. $w_{r} \sqsubseteq_{P} w \equiv \forall z\left[P\left(w_{r}\right)(z) \rightarrow P(w)(z)\right]$

In (27), -sugi is an intensional operator that takes three semantic arguments: a world argument, $w$, a property argument, $P$, and an individual (event

11 In contrast to Stalnaker (1968), Lewis (1973) does not assume the Uniqueness Assumption. He argues that a counterfactual is true in $w$ iff the consequent holds in all possible worlds closest to $w$ where the antecedent is true. On Lewis's account, -sugi would have a meaning like (i) below. $r$ is a free variable ranging over propositions true according to the requirement(s) in the context.

i. $\llbracket$-sugi $\rrbracket^{g}=\lambda w_{s} \lambda P_{\langle s,\langle\tau, t\rangle\rangle} \lambda x_{\tau} \forall w_{s}^{\prime}$ [ $w^{\prime}$ is a possible world closest to $w$ where $r=$ true $\left.\rightarrow\left[P(w)(x) \wedge \neg P\left(w^{\prime}\right)(x) \wedge \forall z_{\tau}\left[P\left(w^{\prime}\right)(z) \rightarrow P(w)(z)\right]\right]\right]$

In (i) -sugi composes with the first two arguments and returns a set of individuals (events or degrees), $x$, such that $P$ is true of $x$ in $w$, but not in any of the closest possible worlds $w^{\prime}$ to $w$ where the relevant requirement is met. Given the scenario in (26), this set is empty, because there is no book that John read in $w$ but not in any possible world closest to $w$ where the requirement is met. Due to this prima facie problem, I remain agnostic on whether the meaning of -sugi should be formulated under Lewis's framework.

12 The analysis of supervaluations is also needed in a scenario where the requirement is to read 'at most' two books (cf. (23)). In such a case, the closest possible world, $w^{\prime}$, to $w$ is any world where John read exactly two of the five books. Any possible world where John read less than two books requires more changes to the evaluation world than $w^{\prime}$, and is therefore considered more distant. The rest of the analysis just follows similarly as that for (26). 
The ingredients of comparison

or degree) argument, $x$, which describes the difference between two sets of entities under comparison. The domain of type $\tau$ includes individuals, events, and degrees. ${ }^{13}$ When -sugi combines with the first two arguments, $w$ and $P$, the result is a set of individuals (events or degrees), $x$, such that $P$ is true of $x$ in $w$ but not in $w_{r}$; for all $z$ such that $P$ is true of $z$ in $w_{r}, P$ is also true of $z$ in $w$.

Besides -sugi, there is another important piece in the structure in (22) which is worth separate consideration, that is, FNQs. As we have seen in the introduction, FNQs associate a sentence with a sole distributive reading. Various analyses have been proposed to capture the distributiviy of FNQs. They are analyzed as either VP quantifiers or adverbs (Fukushima 1991, Nakanishi 2004b, 2007a,b, Kobuchi-Philip 2003, 2007). Because the collective/distributive distinction does not directly concern us here, for ease of exposition, I will simply assume that san-satu in (3) is a generalized quantifier over individuals (of type $\langle\langle e, t\rangle,\langle\langle e, t\rangle, t\rangle\rangle$, as shown in (29). ${ }^{14}$

(29) $\llbracket$ san-satu $\rrbracket=\lambda P_{\langle e, t\rangle} \lambda Q_{\langle e, t\rangle} \cdot \exists x_{e}[\operatorname{satu}(x) \wedge|x| \geq 3 \wedge P(x) \wedge Q(x)]$

Now that we have the meaning of the FNQ san-satu and the meaning of -sugi in place, we are now ready to see how the semantics of (3) is compositionally achieved. (3) has the LF in (30):

13 In the paper, we make use of the following types: type $e$ for individuals, type $d$ for degrees, type $v$ for events, type $s$ for worlds, type $t$ for truth-values, and type $\tau$ for entities including individuals, events, and degrees.

14 In Fukushima (1991), FNQs are VP quantifiers of type $\langle\langle e, t\rangle,\langle\langle e, t\rangle, t\rangle\rangle$; in Kobuchi-Philip (2003, 2007), FNQs are adverbs of type $\langle\langle e, t\rangle,\langle e, t\rangle\rangle$; in Nakanishi (2004b, 2007a,b), FNQs combine with a null operator and form an event modifier of type $\langle\langle v, t\rangle,\langle v, t\rangle\rangle$. In Li (2009), I show how the interpretation of -sugi in (27) is compatible with the analysis of the FNQ in Kobuchi-Philip (2003, 2007). 
(30)

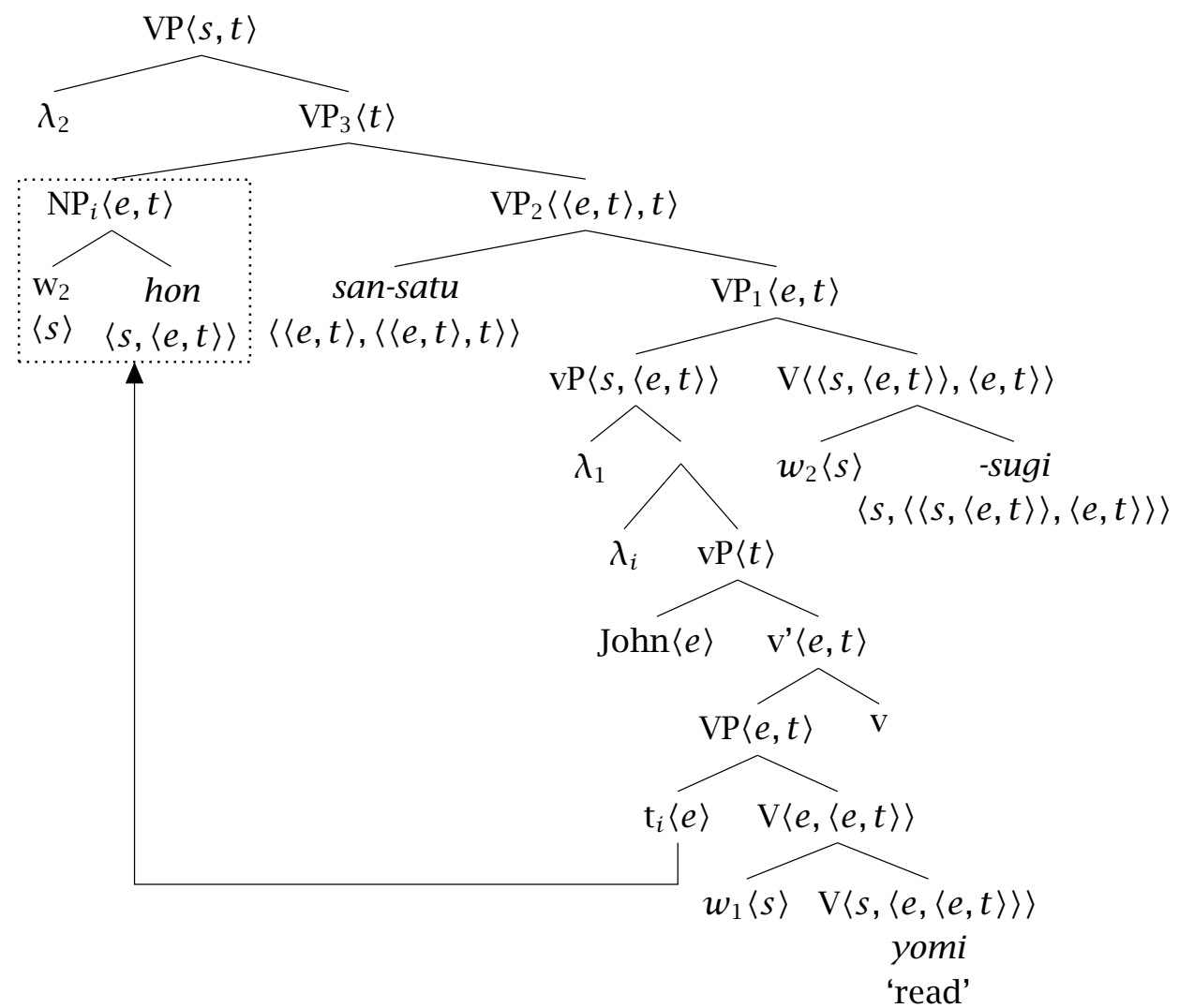

Assuming that nouns and verbs select for a world argument $w$ (of type $\langle s\rangle$ ), (30) can be calculated as follows. ${ }^{15}$ The vP, which is the sentential complement of -sugi, denotes a property of being read by John, as shown in (31b). Inside the $\mathrm{vP}$, there are two lambda abstractors, $\lambda_{1}$ and $\lambda_{i}$. The former binds the world variable, $w_{1}$, introduced by yomi 'to read'; the latter binds the individual variable left by the movement of the host NP. ${ }^{16}$ When the vP composes with [ $w_{2}$-sugi], the result is a set of objects that John read in $w_{2}$ but

15 Following Percus (2000), I assume that possible words can be explicitly represented in the syntax.

16 The LF in (30) contains a non-standard transformation in the framework of Heim \& Kratzer (1998). It is not standard to have $\lambda_{i}$ bind the variable $\mathrm{t}_{i}$ inside the vP rather than right below the moved object, hon 'book'. This operation is motivated by the meaning of -sugi, which seeks a property argument. As an anonymous reviewer pointed out to me, it resembles the operation of 'parasitic scope' discussed in Barker (2007), Kennedy \& Stanley (2009), Bhatt \& Takahashi (2011), Matsui \& Kubota (2010) in that both allow elements to intervene between a lambda abstract created by movement and a moved expression. However, the difference between them lies in that for the operation of parasitic scope, the intervening element is a moved object, whereas for (30), both the FNQ san-satu and the verb -sugi are base-generated. 
not in the closest possible world, $w_{r}$, to $w_{2}$, where the relevant requirement is met, as shown in (31e). The FNQ san-satu and the host NP hon indicate that the set of objects that John read in $w_{2}$ but not in $w_{r}$ is a set of books, whose number is greater than 3 , as shown in (31i).

(31) a. $\llbracket y o m i \rrbracket=\lambda w_{s} \lambda x_{e} \lambda y_{e} \cdot \operatorname{read}(w)(x)(y)$

b. $\llbracket \mathrm{vP} \rrbracket=\lambda w_{1} \lambda t_{e} \cdot \operatorname{read}\left(w_{1}\right)(t)(\mathrm{John})$

c. $\llbracket-$ sugi $_{r} \rrbracket^{g}=\lambda w_{s} \lambda P_{\langle s,\langle e, t\rangle} \lambda x_{e} .\left[P(w)(x) \wedge \neg P\left(w_{r}\right)(x) \wedge w_{r} \sqsubseteq_{P} w\right]$

d. $\llbracket w_{2}-$ sugi $_{r} \rrbracket^{g}=\lambda P_{\langle s,\langle e, t\rangle\rangle} \lambda x_{e} .\left[P\left(w_{2}\right)(x) \wedge \neg P\left(w_{r}\right)(x) \wedge w_{r} \sqsubseteq_{P} w_{2}\right]$

e. $\llbracket \mathrm{VP}_{1} \rrbracket^{g}=\lambda x_{e}$. [ $\left.\operatorname{read}\left(w_{2}\right)(x)(\mathrm{John}) \wedge \neg \operatorname{read}\left(w_{r}\right)(x)(\mathrm{John}) \wedge w_{r} \sqsubseteq_{\text {read }} w_{2}\right]$

f. $\llbracket$ san-satu $\rrbracket^{g}=\lambda P_{\langle e, t\rangle} \lambda Q_{\langle e, t\rangle} . \exists x_{e}[$ $\left.\operatorname{satu}\left(w_{2}\right)(x) \wedge|x| \geq 3 \wedge P(x) \wedge Q(x)\right]$

g. $\llbracket \mathrm{VP}_{2} \rrbracket^{g}=\lambda Q_{\langle e, t\rangle} \cdot \exists x_{e}\left[\operatorname{satu}\left(w_{2}\right)(x) \wedge|x| \geq 3 \wedge \operatorname{read}\left(w_{2}\right)(x)(\mathrm{John}) \wedge\right.$ $\left.\neg \operatorname{read}\left(w_{r}\right)(x)(\mathrm{John}) \wedge w_{r} \sqsubseteq_{\text {read }} w_{2} \wedge Q(x)\right]$

h. $\llbracket h o n \rrbracket=\lambda w_{s} \lambda x_{e} \cdot \operatorname{book}(w)(x)$ $\llbracket w_{2} h o n \rrbracket=\lambda x_{e} \cdot \operatorname{book}\left(w_{2}\right)(x)$

i. $\llbracket \lambda w_{2}$ John-ga hon-o san-satu yomi-sugi-ta $\rrbracket_{r} \rrbracket^{g}=\lambda w_{2} . \exists x_{e}[$ $\operatorname{satu}\left(w_{2}\right)(x) \wedge|x| \geq 3 \wedge \operatorname{book}\left(w_{2}\right)(x) \wedge \operatorname{read}(w)(x)(\mathrm{John}) \wedge$
$\left.\neg \operatorname{read}\left(w_{r}\right)(x)(\operatorname{John}) \wedge w_{r} \sqsubseteq_{\text {read }} w_{2}\right]$

(3ii) is a proposition true of $w_{2}$ iff there is a plural individual $x$ in $w_{2}$ which contains at least three books; John read $x$ in $w_{2}$ but not in $w_{r}$; and for everything John read in $w_{r}$, he also read it in $w_{2}$.

An explanation is in order regarding the last conjunct in (31i), which requires the set of the objects John read in $w_{r}$ to be a proper subset of the set of objects John read in $w_{2}$. This conjunct is motivated to account for a situation like the following. Suppose that John is required to read three specific books, $\{A, B, C\}$, but he read a completely different set, $\{D, E, F, G, H$, I\}. The truth-conditions in (31i) predict (3) to be false in this context, because although there are at least three books John read in the evaluation world $w_{2}$ but not in the closest requirement-compatible world $w_{r}$, it is not the case that for every book that John read in $w_{r}$, he read it in $w_{2}$. (31i) correctly captures the native speaker's intuition about (3) in this context.

Comparing the above analysis to Nakanishi's, the major difference between them lies in whether -sugi is a degree quantifier. For the former, it is not. The -sugi sentence in (3) describes a superset-subset relation of two sets of objects: one in the evaluation world and the other in the closest possible 
world to the evaluation world where the requirement is met. In Nakanishi's analysis, -sugi is a degree quantifier and (3) expresses an ordering of two degrees.

In fact, Nakanishi's analysis and my analysis demonstrate two possible ways of comparing the sizes of two sets. Suppose we have two sets, $S$ and $S^{\prime} . S$ is $\{\mathrm{A}, \mathrm{B}, \mathrm{C}, \mathrm{D}, \mathrm{E}, \mathrm{F}\}$ and $S^{\prime}$ is $\{\mathrm{A}, \mathrm{B}, \mathrm{C}\}$. We can show that $\mathrm{S}$ is a bigger set than $S^{\prime}$ by showing that the cardinality of $S$ (i.e., $|S|=6$ ) is greater than the cardinality of $S^{\prime}$ (i.e., $\left|S^{\prime}\right|=3$ ). Alternatively, we can compare $S$ and $S^{\prime}$ without referring to numbers (or degrees). That is, given that $S$ is a proper superset of $S^{\prime}$ (i.e., every element in $S^{\prime}$ is contained in $S$ and there are elements in $S$ but not in $S^{\prime}$ ), $S$ is bigger than $S^{\prime}$. Nakanishi's analysis demonstrates the first approach, the degree-based approach, while my analysis demonstrates the second approach, the degree-less approach.

As the degree-based and degree-less approaches always yield the same result, Nakanishi's analysis and my analysis are essentially truth-conditionally equivalent. However, there is an important difference between them, which has to do with differentials in comparatives. For the degree-based approach, the difference between two degrees is necessarily a degree. Therefore, it predicts that differentials of comparatives are degree-denoting expressions, for example, measure phrases. For the degree-less approach, the difference between two sets (of individuals, events, or degrees) is another set (of individuals, events, or degrees). Differentials of comparatives are expressions that can quantify over (or modify) the difference between the two sets. In the -sugi construction in (3), FNQs quantify over the difference between two sets of individuals under comparison.

A -sugi sentence compares not only two sets of individuals, but also two (sets of) events. In the latter case, a measure phrase can serve as a differential. This is illustrated by the example in (32).

(32) John-ga san-mairu oyogi-sugi-ta

John-NOM 3-mile swim-exceed-PAST

'John swam three miles too far.'

(Nakanishi 2007a: 201)

In (32), -sugi combines with an intransitive verb oyogi 'to swim'. The differential is a measure phrase san-mairu 'three miles'. Intuitively, (32) compares two events: a swimming event that John did, $e$, and a swimming event that John would have done had he met the requirement, $e^{\prime}$. (32) is true in a scenario like the following. 
The ingredients of comparison

(33) Scenario: In a swimming class, the coach requires everyone to swim no more than three miles. John violated this requirement by swimming six miles.

According to the scenario in (33), $e$ is an event of John swimming six miles in the evaluation world; $e^{\prime}$ is an event of John swimming three miles in the closest requirement-compatible world. The difference between $e$ and $e^{\prime}$ is a swimming event, $e^{\prime \prime}$, which extends three miles. Hence, $e=e^{\prime}+e^{\prime \prime}$, as demonstrated by the diagram in (34). ${ }^{17}$

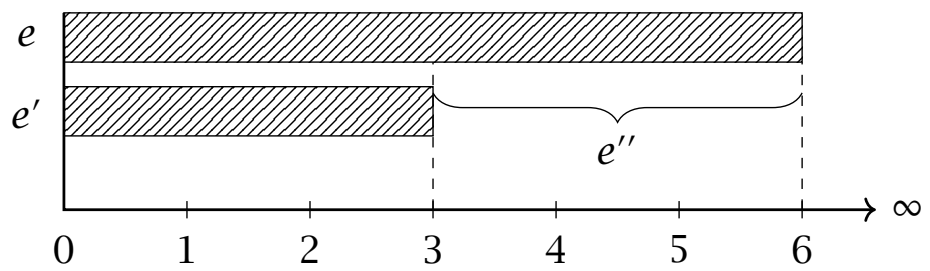

Measure phrases are cross-categorial (Winter 2005). They can appear with different linguistic elements and receive different interpretations. As we have seen in the introduction, measure phrases can serve as differentials in adjectival comparatives to describe the difference between two degrees under comparison. Also, they can appear with verbs and be used as adverbials, as shown by the example in (35):

(35) John-ga san-mairu oyoida

John-NOM 3-mile swim-PAST

'John swam three miles.'

The example in (35) minimally differs from (32) in the absence of -sugi. In (35), san-mairu 'three miles' is an adverbial, which, in Davidsonian semantics, can be interpreted as an event modifier, as shown in (36b):
a. $\llbracket J o h n-g a$ oyogi-ta $\rrbracket=\lambda e_{v}$. $[\operatorname{Agent}(e)=\operatorname{John} \wedge \operatorname{swim}(e)]$
b. $\llbracket$ san-mairu $\rrbracket=\lambda E_{\langle v, t\rangle} \lambda e_{v}[E(e) \wedge 3 \operatorname{miles}(e)]$

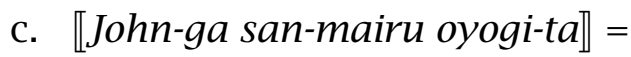
$\lambda e_{v}[\operatorname{Agent}(e)=\operatorname{John} \wedge \operatorname{swim}(e) \wedge 3 \operatorname{miles}(e)]$

17 I assume that events have transworld identity; they may exist in more than one possible world. In (34), $e^{\prime}$, as a subevent of $e$, exists in the evaluation world, $w$, and the closest requirement-compatible world, $w_{r}$. 
In (36), san-mairu takes a set of events of John's swimming and returns a set of events of John's swimming three miles.

If we incorporate the meaning of the adverbial measure phrase in (36b) into the semantics of the -sugi sentence in (32), (32) can be interpreted as follows. Suppose (32) has the LF in (37).

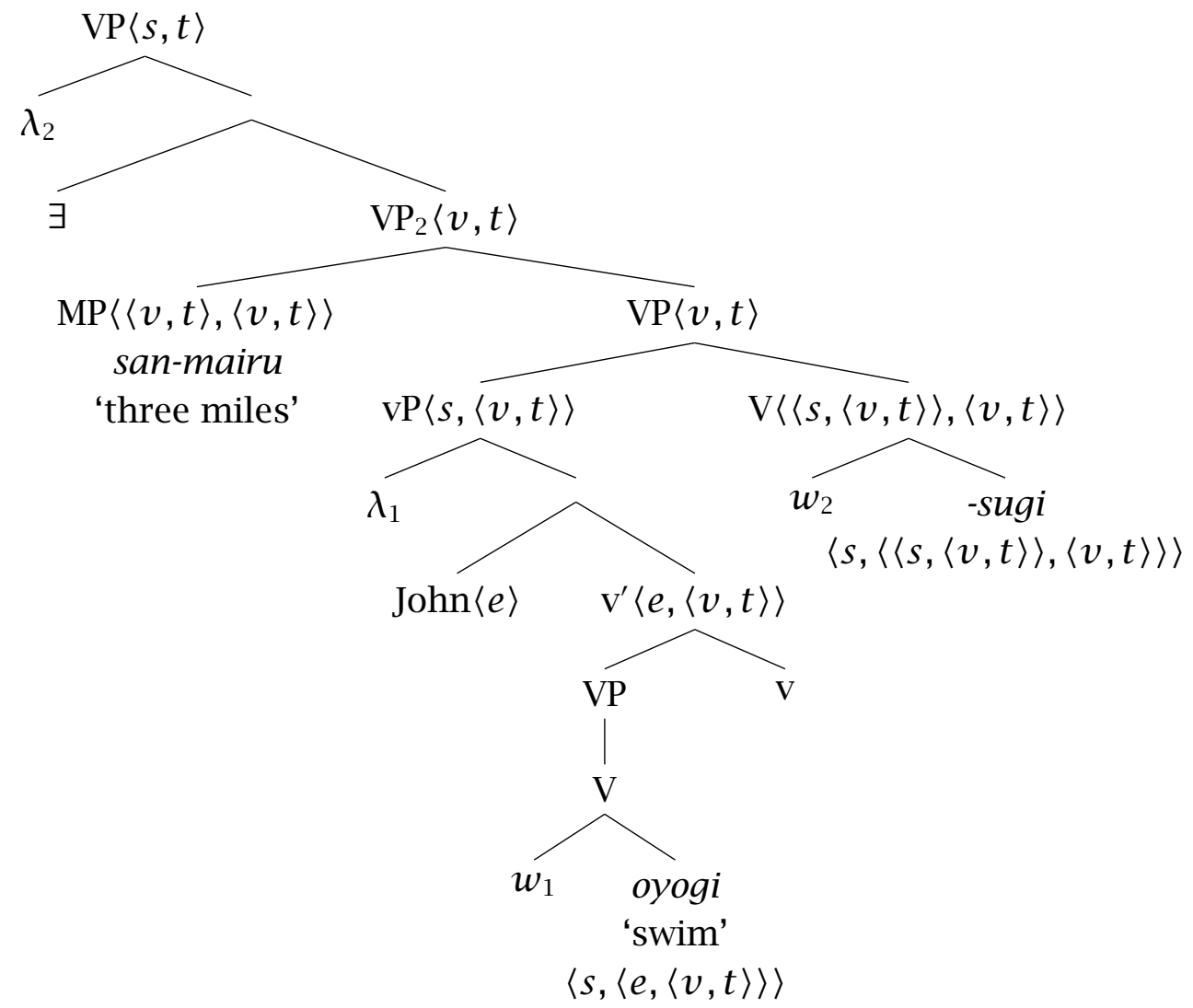

The vP in (37) denotes a property of events of John's swimming, as shown in (38b). When the vP composes with -sugi, the result is a set of events, $e$, such that $e$ is an event of John's swimming in $w_{2}$, but not an event of his swimming in the closest possible world, $w_{r}$, to $w_{2}$, where the requirement is met, as shown in (38e). The adverbial measure phrase san-mairu indicates that $e$ is three miles, as shown in (38f). Assuming that $e$ is existentially bound at the end of the calculation, (32) has the truth-conditions in (38i).
a. $\llbracket$ oyogi $\rrbracket=\lambda w_{s} \lambda x_{e} \lambda e_{v} \cdot[\operatorname{Agent}(w)(e)=x \wedge \operatorname{swim}(w)(e)]$
b. $\llbracket \mathrm{vP} \rrbracket=\lambda w_{1 s} \lambda e_{v} \cdot\left[\operatorname{Agent}(w)(e)=\operatorname{John} \wedge \operatorname{swim}\left(w_{1}\right)(e)\right]$
c. $\llbracket-s u g i_{r} \rrbracket^{g}=\lambda w_{s} \lambda P_{\langle s,\langle v, t\rangle\rangle} \lambda x_{v} .\left[P(w)(x) \wedge \neg P\left(w_{r}\right)(x) \wedge w_{r} \sqsubseteq_{P} w\right]$ 
The ingredients of comparison

d. $\llbracket w_{2}$-sugi $\rrbracket^{g}=\lambda P_{\langle s,\langle v, t\rangle\rangle} \lambda x_{v} .\left[P\left(w_{2}\right)(x) \wedge \neg P\left(w_{r}\right)(x) \wedge w_{r} \sqsubseteq_{P} w_{2}\right]$

e. $\llbracket \mathrm{VP}_{1} \rrbracket^{g}=\lambda x_{v}$. $\left[\left[\operatorname{Agent}\left(w_{2}\right)(x)=\operatorname{John} \wedge \operatorname{swim}\left(w_{2}\right)(x)\right] \wedge\right.$ $\left.\neg\left[\operatorname{Agent}\left(w_{r}\right)(x)=\operatorname{John} \wedge \operatorname{swim}\left(w_{r}\right)(x)\right] \wedge w_{r} \sqsubseteq_{\text {swim }} w_{2}\right]$

f. $\llbracket$ san-mairu $\rrbracket=\lambda E_{\langle v, t\rangle} \lambda e_{v} \cdot[E(e) \wedge 3 \operatorname{miles}(e)]$

g. $\llbracket \mathrm{VP}_{2} \rrbracket^{g}=\lambda e_{v} \cdot\left[\left[\operatorname{Agent}\left(w_{2}\right)(e)=\operatorname{John} \wedge \operatorname{swim}\left(w_{2}\right)(e)\right] \wedge\right.$ $\left.\neg\left[\operatorname{Agent}\left(w_{r}\right)(e)=\operatorname{John} \wedge \operatorname{swim}\left(w_{r}\right)(e)\right] \wedge 3 \operatorname{miles}(e) \wedge w_{r} \sqsubseteq_{\text {swim }} w_{2}\right]$

h. $\llbracket \exists \rrbracket=\lambda P_{\langle v, t\rangle} \cdot \exists e_{v} P(e)$ $\llbracket \exists \mathrm{VP}_{2} \rrbracket^{g}=\exists e_{v}\left[\left[\operatorname{Agent}\left(w_{2}\right)(e)=\operatorname{John} \wedge \operatorname{swim}\left(w_{2}\right)(e)\right] \wedge\right.$ $\left.\neg\left[\operatorname{Agent}\left(w_{r}\right)(e)=\operatorname{John} \wedge \operatorname{swim}\left(w_{r}\right)(e)\right] \wedge 3 \operatorname{miles}(e) \wedge w_{r} \sqsubseteq_{\text {swim }} w_{2}\right]$ (by Existential Closure)

i. $\llbracket \lambda w_{2} J o h n-g a$ san-mairu oyogi-ta $\rrbracket^{g}=\lambda w_{2} \cdot \exists e_{v}[$

$$
\begin{aligned}
& \text { [Agent } \left.\left(w_{2}\right)(e)=\operatorname{John} \wedge \operatorname{swim}\left(w_{2}\right)(e)\right] \wedge \\
& \neg\left[\operatorname{Agent}\left(w_{r}\right)(e)=\operatorname{John} \wedge \operatorname{swim}\left(w_{r}\right)(e)\right] \wedge \\
& \text { swim three } \left.\operatorname{miles}(e) \wedge w_{r} \sqsubseteq_{\text {swim }} w_{2}\right]
\end{aligned}
$$

(38i) is a proposition true of $w_{2}$ iff there is some event $e$ of John's swimming in $w_{2}$, but not in $w_{r}$; $e$ is three miles; and for all the swimming that John did in $w_{r}$, he also did it in $w_{2}$.

As $r$ in $w_{r}$ can range over any requirement in the context, an anonymous reviewer raises the question of whether it is sufficiently constrained. For example, does the analysis correctly predict the sentence in (40) to be false in a scenario like (39), where $r$ does not refer to an 'amount' requirement? In (39), the requirement is on the maximal speed that one can reach rather than the maximal amount of swimming that one can do. John violated the requirement by swimming faster than allowed.

(39) Scenario: In a swimming class, the coach requires everyone to swim at the maximal speed of $3 \mathrm{mph}$. John swam three miles at the speed of 4 mph.

(40) John-ga aoyogi-sugi-ta.

John-NOM swim-exceed-PAST

'John over-swam.'

(41) $\llbracket(40) \rrbracket=\lambda w_{2} \exists e_{v} \cdot\left[\left[\operatorname{Agent}\left(w_{2}\right)(e)=\operatorname{John} \wedge \operatorname{swim}\left(w_{2}\right)(e)\right] \wedge\right.$

$$
\left.\neg\left[\operatorname{Agent}\left(w_{r}\right)(e)=\operatorname{John} \wedge \operatorname{swim}\left(w_{r}\right)(e)\right] \wedge w_{r} \sqsubseteq_{\text {swim }} w_{2}\right]
$$

Given the scenario in (39), the two events under comparison are: event $e$ of John's swimming three miles at the speed of $4 \mathrm{mph}$ in the evaluation 
world $w_{2}$, and event $e^{\prime}$ of John's swimming three miles at the speed of 3 $\mathrm{mph}$ in the closest requirement-compatible world $w_{r}$. Any possible world where John swam longer than three miles at the required speed demands more changes on the evaluation world than $w_{r}$, and is thus considered more distant. Comparing $e$ to $e^{\prime}$, they do not stand in a part-whole relation (or a superset-subset relation) as in (34).

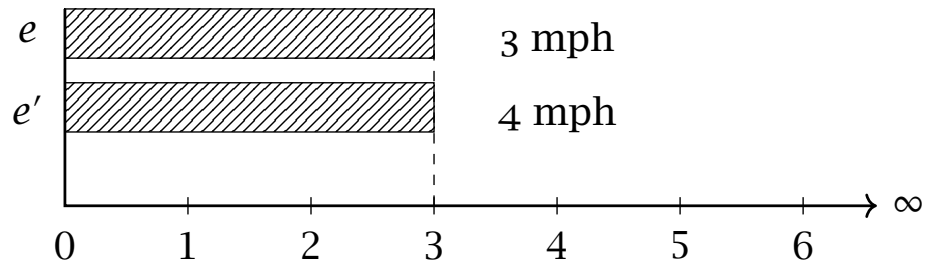

Under the proposed analysis, (40) has the truth-conditions in (41), which correctly predict (40) to be false in (39), because it is not the case that there is some event of John swimming in $w_{2}$ but not in $w_{r}$, as required by the first two conjuncts in (41). ${ }^{18}$

To summarize, in this subsection I have examined the semantics of -sugi when it combines with a non-gradable verb. I argued that a V-sugi sentence describes a comparison of two sets of individuals or events. The differential of a V-sugi sentence can be either a FNQ which quantifies over the difference between two sets of individuals or a measure phrase which modifies the difference between two (sets of) events.

This analysis fares better than Nakanishi's analysis in at least two aspects. First, it is more economical, as it keeps the syntax and semantics of FNQs consistent in -sugi and non-sugi contexts, and it renders the implicit predicate $M A N Y$ unnecessary. Second, the proposed analysis is also more compositional. As we have seen in Section 2, Nakanishi's analysis makes crucial use of the homomorphism $h$ that can freely map from events to their patients, temporal trace, and spacial extent. As such, it may give rise to unattested readings, as shown in (12) (repeated below). In my analysis, the choice of reading (i.e., excess of individuals/events/degrees) is decided compositionally by the position of (non-)FNQs, and the predicate that -sugi combines with. (12) is predicted not to have the excess of individuals reading - 'John read three books, and that was too much.', because the object hon san-satu 'three books'

18 There is also a question of whether $e$ and $e^{\prime}$ with different speeds are considered to be the same event or two different events. In the latter case, the condition expressed by the last conjunct in (41) is not satisfied, i.e., it is not the case that all the events of John swimming in $w_{r}$ are the events of John swimming in $w$. 
The ingredients of comparison

is situated in the object position inside the $\mathrm{vP}$, which denotes a property of events. ${ }^{19}$

(12) John-ga [hon san-satu]-o kinoo yomi-sugi-ta.

John-NOM book 3-Cl-ACC yesterday read-exceed-PAST

'John over-read (the) three books yesterday.'

NOT: 'John read three books, and that was too much.'

In the following subsection, I will turn to the situation where -sugi combines with a gradable adjective. I show that an Adj-sugi sentence has an excess of degrees reading, which can be captured by the non-degree-based analysis proposed in this subsection.

\section{2 -sugi and gradable adjectives}

Let us consider the example in (2) (repeated below), where -sugi combines with the gradable adjective naga 'long'.

(2) Kono pantsu-ga ni inchi naga-sugi-ru.

this pant-NOM 2 inch long-exceed-present

'This pair of pants is two inches too long.'

(2) is true, for example, in a situation where this pair of pants is required to be exactly 34 inches long, but is actually 36 inches long. The analysis of -sugi in the previous subsection can correctly capture the truth-value of (2) in this context. Suppose $w$ is the evaluation world. The set of degrees of length that this pair of pants possesses in $w$ is all the degrees below 36 inches, written as $\{d: d \leq 36$ " $\}$. The closest possible world, $w_{r}$, to $w$, where the requirement is met is the world where this pair of pants is exactly 34 inches. Thus, the set of degrees of length that the pants possess in $w_{r}$ is all the degrees below 34 inches, written as $\left\{d^{\prime}: d^{\prime} \leq 34\right.$ " $\}$. The difference between $\left\{d: d \leq 36^{\prime \prime}\right\}$ in $w$ and $\left\{d^{\prime}: d^{\prime} \leq 34\right.$ " $\}$ in $w_{r}$ is the set of degrees ranging from 34 to 36 inches, written as $\left\{d^{\prime \prime}: 34 "<d<36\right.$ " $\}$, which spans two inches on a scale of length. This is shown by the diagram in (43):

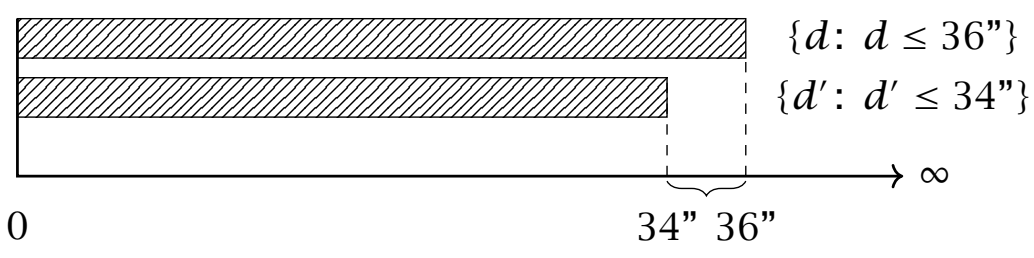

19 There is more discussion on the semantics of (12) in the appendix. 
Below I show how the meaning of (2) is computed based on the LF in (44).

(44)

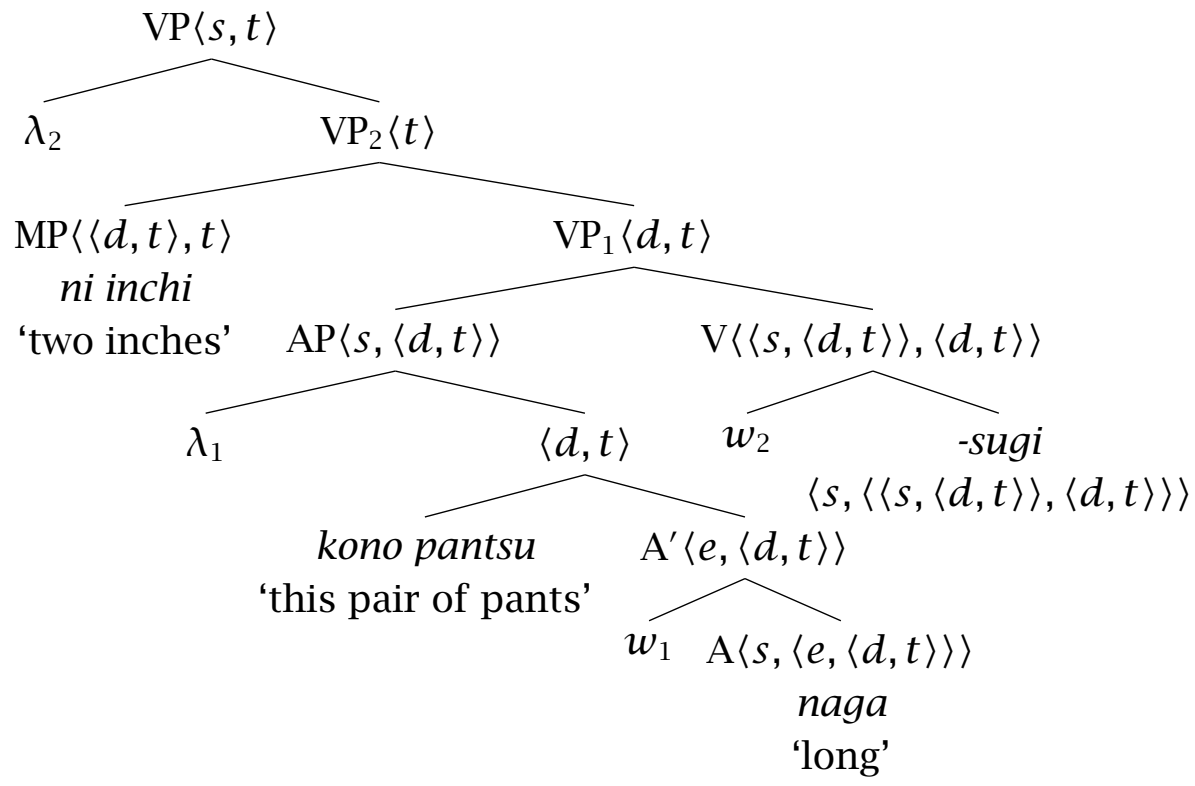

In (44), I assume that the adjective naga 'long' has the semantics in (45a), which is a relation between possible world $w$, individual $x$ and degree $d$ such that $x$ is long to degree $d$ in $w .^{20}$ The AP kono pantsu naga denotes a property of degrees, as shown in (45b). When the AP composes with -sugi, it yields a set of degrees to which this pair of pants is long in $w$ but not in the closest requirement-compatible world $w_{r}$, as shown in (45c-e). Following Schwarzschild (2005) and McConnell-Ginet (1973), I assume that measure phrases are predicates of gaps. The measure phrase ni inchi ' 2 inches' in (38) is a predicate of the set of degrees to which the pants is long in $w$ but not in $w_{r}$, as shown in (45f-h).
a. 【naga $\rrbracket=\lambda w_{s} \lambda x_{e} \lambda d_{d} \cdot \operatorname{long}(w)(x)(d)$
b. $\llbracket \mathrm{AP} \rrbracket=\lambda w_{1} \lambda d_{d} \cdot \operatorname{long}\left(w_{1}\right)($ pants $)(x)$
c. $\llbracket$-sugi $\rrbracket_{r} \rrbracket^{g}=\lambda w_{s} \lambda P_{\langle s,\langle d, t\rangle\rangle} \lambda x_{d} .\left[P(w)(x) \wedge \neg P\left(w_{r}\right)(x) \wedge w_{r} \sqsubseteq_{P} w\right]$
d. $\llbracket w_{2}-$ Sugi $_{r} \rrbracket^{g}=\lambda P_{\langle s,\langle d, t\rangle\rangle} \lambda x_{d} \cdot\left[P\left(w_{2}\right)(x) \wedge \neg P\left(w_{r}\right)(x) \wedge w_{r} \sqsubseteq_{P} w_{2}\right]$
e. $\llbracket \mathrm{VP}_{1} \rrbracket^{g}=\lambda x_{d}$. $\left[\operatorname{long}\left(w_{2}\right)(x)\right.$ (pants) $\wedge \neg \operatorname{long}\left(w_{r}\right)(x)$ (pants) $\wedge$$$
\left.w_{r} \sqsubseteq_{\text {long }} w_{2}\right]
$$

f. $\llbracket n i$ inchi $\rrbracket=\lambda D_{\langle d, t\rangle} \cdot 2 \operatorname{inches}(D)$

20 A more common semantic type for adjectives is type $\langle s,\langle d,\langle e, t\rangle\rangle\rangle$. Alternatively, they can also be analyzed as measure functions of type $\langle e, d\rangle$ (Bartsch \& Vennemann 1972, Kennedy 1997). 
The ingredients of comparison

$$
\begin{aligned}
& \text { g. } \llbracket \mathrm{VP}_{2} \rrbracket^{g}=2 \text { inches }\left(\lambda x _ { d } \cdot \left[\operatorname{long}\left(w_{2}\right)(x)(\text { pants }) \wedge\right.\right. \\
&\left.\left.\neg \operatorname{long}\left(w_{r}\right)(x)(\text { pants }) \wedge w_{r} \sqsubseteq_{\text {long }} w_{2}\right]\right) \\
& \text { h. } \llbracket(2) \rrbracket^{g}=\lambda w_{2}\left[2 \text { inches } \left(\lambda x _ { d } \cdot \left[\operatorname{long}\left(w_{2}\right)(x)(\text { pants }) \wedge\right.\right.\right. \\
&\left.\left.\left.\neg \operatorname{long}\left(w_{r}\right)(x)(\text { pants }) \wedge w_{r} \sqsubseteq_{\text {long }} w_{2}\right]\right)\right]
\end{aligned}
$$

(45h) is a proposition true of $w_{2}$ iff the set of degrees to which this pair of pants is long in $w_{2}$ but not in $w_{r}$ spans two inches on a scale of length; and all the degrees of length that this pair of pants possesses in $w_{r}$ are a proper subset of the degrees of length that it possesses in $w_{2}$.

\subsection{Summary}

In this section, I have mainly considered the meaning of -sugi in two situations: when it combines with a non-gradable verb and when it combines with a gradable adjective. In each case, a semantically different type of phrase can be used as a differential: in the former, a FNQ can be a differential, and in the latter, a measure phrase can be a differential. I proposed a unified interpretation of -sugi while maintaining the semantic difference between FNQs and measure phrases. I argued that -sugi is not a degree quantifier. Depending on whether -sugi combines with an adjective or a verb, a -sugi sentence can describe a comparison of two sets of degrees, individuals or events in the evaluation world and in the closest possible world to the evaluation world where the requirement is met.

If this proposed analysis of -sugi is correct, it implies that degrees are not a necessary ingredient in the semantics of comparison. One might wonder how such an analysis relates to the existing literature on the semantics of comparison, especially the degree-based analyses of comparatives. In the following section, I show that the non-degree-based analysis of -sugi in fact draws an interesting parallel to the degree-based A-not-A analysis of comparatives in the literature.

\section{4 -sugi and the A-not-A analysis}

On the degree-based analyses of the comparative, an adjectival comparative such as the one in (46) can be paraphrased in at least two possible ways, as shown in (47). (47a) says: (46) is true iff the maximal degree to which A is long is greater than the maximal degree to which B is long. (47b) says: (46) is true iff there is a degree of length that A meets or exceeds but B does not. 
(47b) can be alternatively expressed as $\{d$ : A is d-long $\} \supset\left\{d^{\prime}: B\right.$ is d'-long $\}$, which invokes set complementation rather than negation.

(46) A is longer than B is.

(47) a. $\max \{d$ : A is $d$-long $\}>\max \left\{d^{\prime}:\right.$ B is $d^{\prime}$-long $\}$

'the greater-than analysis'

b. $\exists d[\operatorname{long}(d)(\mathrm{A}) \wedge \neg \operatorname{long}(d)(\mathrm{B})]$

'the A-not-A analysis'

The two formulas in (47a) and (47b) are truth-conditionally equivalent. Nonetheless, they suggest different things about the contribution of the comparative. In (47a) the comparative contributes a greater-than relation; in $(47 \mathrm{~b})$ it contributes a proper subset relation (expressed through conjunction and negation). I refer to the analysis in (47a) as the greater-than analysis and the one in $(47 \mathrm{~b})$ as the A-not-A analysis. ${ }^{21}$

The greater-than analysis and the A-not-A analysis, though extensionally equivalent, carry different predictions about what predicates the comparative morpheme can combine with. The former predicts that the comparative morpheme can only combine with a gradable predicate, because the greater than relation makes reference to the ordering of degrees and it is assumed that only the semantics of gradable predicates contain degrees. The latter, on the other hand, predicts that the comparative morpheme can combine with either a gradable or a non-gradable predicate, because the comparative morpheme encodes a proper subset relation that is compatible with sets of degrees, individuals and events. For languages like English where the comparative morpheme only selects for a gradable adjective, we can choose either the greater than analysis or the A-not-A analysis to capture the truthconditions of (46), as the comparison is only between degrees. However, when one turns to languages like Japanese where the comparative morpheme can combine with a gradable or a non-gradable predicate, the A-not-A analysis fares better, because it is naturally compatible with comparisons of degrees and non-degrees. Below I briefly show that the analysis of -sugi proposed in this paper is an instance of the A-not-A analysis.

To illustrate the parallel between the analysis of -sugi and the A-not-A analysis, I will first spell out the truth-conditions of the too-construction in (48) under the A-not-A analysis. As we have previously seen in Nakanishi's analysis, the semantics of (48a) can be described as a comparison between the

21 The term 'A-not-A' is borrowed from Schwarzschild (2008). This analysis is also discussed in Seuren (1973, 1984), McConnell-Ginet (1973), Kamp (1975), Hoeksema (1983), among others. 
maximal degree to which $\mathrm{A}$ is long and a contextually supplied standard $C$. If we flesh out the value of $C$, it is determined by the counterfactual conditional like If A met the requirement, it would have been $C$-long. Under Stalnaker's analysis of counterfactual conditionals, $C$ is the maximal degree to which A is long in the closest possible world to the evaluation world where the requirement is met. Therefore, the truth-conditions of (48a) can be stated in (48b), which says: (48a) is true in $w$ iff there is a degree to which A is long in $w$, but not in the closest requirement-compatible world $w_{r}$.

(48) a. A is too long.

b. $\lambda w_{s} \cdot \exists d_{d}\left[\operatorname{long}(w)(d)(\mathrm{A}) \wedge \neg \operatorname{long}\left(w_{r}\right)(d)(\mathrm{A})\right]$

If we add a differential measure phrase like 2 inches to (48a), it then has the truth-conditions in $(49 \mathrm{~b})$, where the measure phrase indicates that the set of degrees to which $\mathrm{A}$ is long in $w$, but not in $w_{r}$ spans two inches.

(49) a. A is two inches too long.

b. $\lambda w_{s}\left[2 \operatorname{inches}\left(\lambda d_{d}\left[\operatorname{long}(w)(d)(\mathrm{A}) \wedge \neg \operatorname{long}\left(w_{r}\right)(d)(\mathrm{A})\right]\right)\right]$

Comparing (49b) to (45g), the two interpretations minimally differ in the last conjunct which specifies a superset-subset relation between the two sets in the evaluation world and the closest requirement-compatible world. This conjunct, though vacuously satisfied in degree comparison, is motivated to account for examples where -sugi combines with a non-gradable verb and the comparison is between two sets of objects, as already shown in Section 3.1.

\section{Conclusion}

In the paper, I have looked at the excessive construction in Japanese which involves the morpheme -sugi 'to exceed'. Unlike any degree morpheme in English, -sugi in Japanese can combine with either a gradable adjective or a non-gradable verb to express an excessive meaning. In each case, a semantically different type of phrase can be used as a differential: when -sugi combines with an adjective, a measure phrase can be used as a differential; when -sugi combines with a verb, a FNQ can be used as a differential. Based on this observation, I put forward a non-degree based analysis in which -sugi is not a degree quantifier. This analysis is compared to the degree-based analysis proposed in Nakanishi (2004a, 2004b, 2007b) and argued to be superior, because it maintains the syntax and semantics of FNQs in -sugi and 
non-sugi sentences, and renders unnecessary the implicit predicate MANY whose function is to relate predicates whose semantics do not contain a degree to a degree.

If what I have said above is correct, the analysis of -sugi brings new material to be considered in the discussion of competing theories of comparison, as it implies that degrees are not a necessary ingredient in the semantics of comparison. It shows that the A-not-A analysis, which is originally proposed to account for degree comparison, is compatible with comparisons of objects and events, and thus encodes a more general notion of comparison than analyses based on the ordering of degrees.

Finally, it is worth pointing out that the proposed analysis of -sugi constitutes a departure from the current literature on Japanese degreeconstructions, which mostly focus on constructions where the degree morphology combines with a gradable adjective and are degree-based (Beck, Oda \& Sugisaki 2004, Aihara 2009, Kennedy 2007, Oda 2008, Bhatt \& Takahashi 2011, Sawada \& Grano 2011, Shimoyama 2012). Our study of -sugi suggests that languages may vary with respect to whether they make exclusive use of degrees in the expression of comparison. English seems to be a language where degree constructions are solely degree-based; Japanese, on the other hand, belongs to a different typological group.

\section{Appendix}

In this section, I mainly consider two issues. One is the ambiguity of the -sugi sentence in (3) and the other is the subject-oriented FNQs in the -sugi construction. Let us start with the ambiguity of (3). In addition to the reading'yesterday John over-did the reading by three books', (3) also has a less salient reading-'yesterday John over-read (the) three books' (e.g., John is required to read the three books only twice, but he read them five times).

(3) John-ga hon-o kinoo san-satu yomi-sugi-ta. John-NOM book-ACC yesterday 3-Cl read-exceed-PAST

i. 'Yesterday John over-did the reading by three books.'

ii. 'Yesterday John over-read (the) three books.'

I argue that this non-salient reading is associated with another possible structure of (3), as shown in (50): 
The ingredients of comparison

(50)

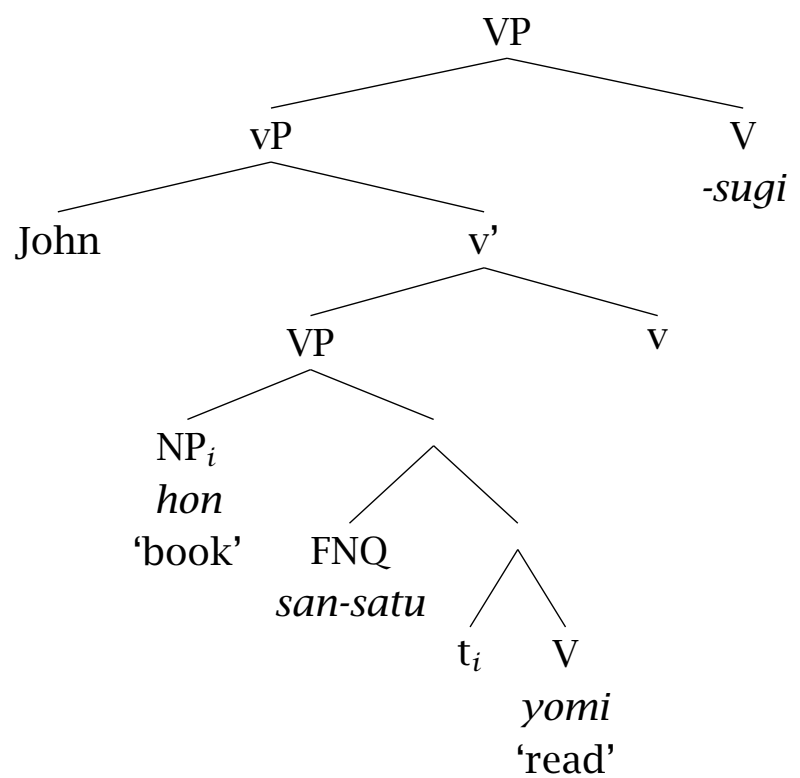

Like the structure in (22) which is associated with the salient reading 'John over-did the reading by three books', (50) is based on the two assumptions that (i) the object-oriented FNQ are VP adverbs, and (ii) -sugi is a raising verb that takes a vP complement. However, unlike (22), (50) has the FNQ attached to the VP inside the vP.

Semantically, (50) can be interpreted in a similar fashion as the sentence in (12) (repeated below), which has the structure in (51):

(12) John-ga [hon san-satu]-o kinoo yomi-sugi-ta.

John-NOM book 3-Cl-ACC yesterday read-exceed-PAST

'John over-read (the) three books yesterday.'

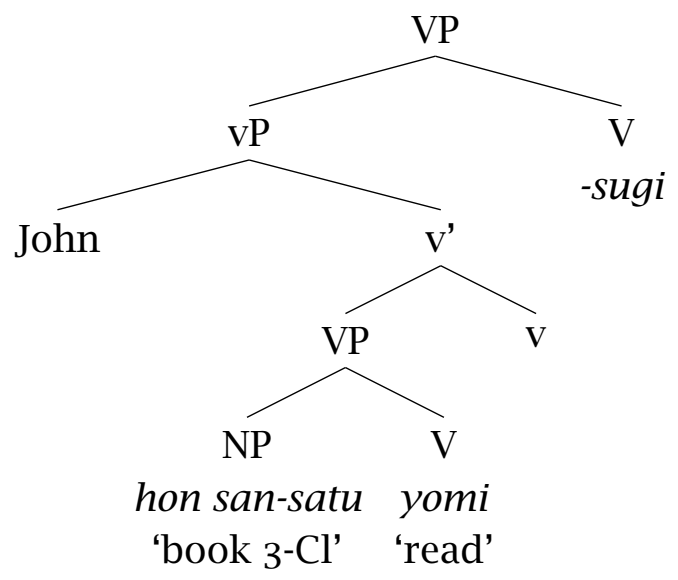


Like the non-FNQ san-satu in (51), the FNQ san-satu and the host NP hon 'books' in (50) are situated inside the vP. On our analysis, the vP denotes a property of events of John reading three books. When it combines with -sugi, the result is a set of events of John reading (the) three books in the evaluation world $w$, but not in the closest possible world, $w_{r}$, to $w$, where the reading requirement is met. We can add a differential such as san-jikan ' 3 hours' in (3) and (12), as shown in (52) and (53) respectively, to indicate that the set of events of John reading (the) three books in $w$ but not in $w_{r}$ measures three hours.

(52) John-ga hon-o kinoo san-satsu san-jikan yomi-sugi-ta. John-NOM book-ACC yesterday 3-Cl 3 hours read-exceed-PAST

'John over-read (the) three books by three hours yesterday.'

(53) John-ga [hon san-satu]-o kinoo san-jikan yomi-sugi-ta. John-NOM book 3-Cl-ACC yesterday 3 hours read-exceed-PAST

'John over-read (the) three books by three hours yesterday.'

Given the above discussion, the semantic ambiguity of (3) can be attributed to the syntactic ambiguity between the two structures in (22) and (50), each of which has a different scope between the FNQ and -sugi. ${ }^{22}$ When the FNQ is above -sugi, the sentence means: 'John over-did the reading by three books'; when the FNQ is below -sugi, the sentence means: 'John over-read (the) three books.'

Another issue which I consider in this appendix is the subject-oriented FNQ in -sugi sentences. Nakanishi (2004b, 2007a) observes that unlike objectoriented FNQs, subject-oriented FNQs are not allowed in -sugi sentences, as shown in (54). Based on this observation, she argues that FNQs in -sugi sentences are different from those in non-sugi sentences: the former are arguments of -sugi, while the latter are adverbs. I will show that examples like (54b) do not constitute conclusive evidence for Nakanishi's claim.

22 Note that a similar type of scope ambiguity is observed between -sugi and dake 'only', as shown in (20) (repeated below):

(20) John-wa niku-dake-o tabe-sugi-ta.

John-TOP meat-only-ACC eat-exceed-PAST

i. only > sugi (Among many things John ate, it is only meat that he overate)

ii. sugi $>$ only (For too a long time, John ate nothing but meat)

(Koizumi 1998: 5) 
The ingredients of comparison

(54) a. Gakusei-ga kinoo san-nin sono miitingu-ni sankasi-ta. student-NOM yesterday 3-Cl that meeting-in participate-PAST

'Three students participated in that meeting yesterday.'

b. ??Gakusei-ga kinoo san-nin sono miitingu-ni student-NOM yesterday 3 -Cl that meeting-in sankasi-sugi-ta.

participate-exceed-PAST

(Nakanishi 2007a: 209)

It has been independently argued that subject-oriented FNQs like san-nin in (54a) are vP adverbs (Fukushima 1991, Fujita 1994, Kobuchi-Philip 2003, 2007). Evidence for this claim comes from the conjunction test below. In (55), the subject-oriented FNQs are conjoined with the sentential adverbs tashikani 'certainly' and kotogotoku 'entirely' respectively.

(55) a. Shoonin-ga, san-nin katsu tashikani sono jiko-o witness-NOM 3-Cl and certainly the accident-ACC mokugekishita.

witnessed

'Three witnesses witnessed the accident for certain.'

b. Terorisuto-ga, juи-nin katsu kotogotoku taiho-sare-ta terrorist-NOM $10-\mathrm{Cl}$ and entirely arrest-pass-PAST 'All ten terrorist were arrested.'

(Kobuchi-Philip 2003: 18)

The assumptions that (i) subject-oriented FNQs are vP adverbs and (ii) sugi takes a vP complement predict that (54b) has only one possible structure, as shown in (56). 
(56)

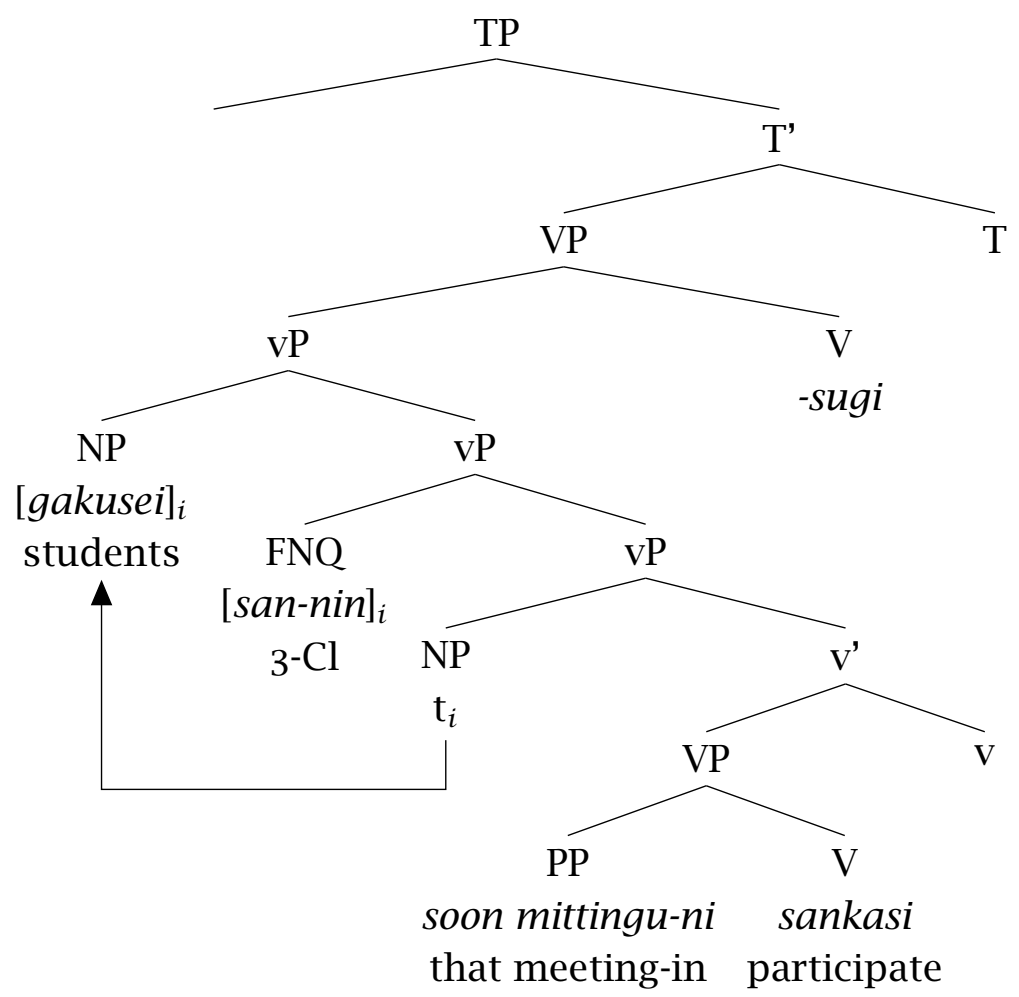

In (56) the FNQ san-nin is a vP adverb that is adjoined to the vP. The host NP gakusei 'students' is moved to c-command san-nin, and is co-indexed with it.

Comparing the structure in (56) to the one in (50), both have a FNQ below -sugi: in (56) it is the subject-oriented FNQ san-nin, and in (50) it is the objectoriented FNQ san-satu. Given that in my analysis only the FNQ above -sugi can be interpreted as a differential, (56) is predicted to mean: 'three students participated in that meeting too much.'

Here is what we found by consulting the native Japanese speakers about the reading of $(54 \mathrm{~b})$. For most of them, (54b) is a marginally acceptable sentence. If it ever has a reading, it is the reading 'three students participated in that meeting too much' rather than 'three students too many participated in that meeting.' Their judgment is in fact consistent with our prediction above.

Now the question is: why is the subject-oriented FNQ san-nin only allowed in a non sugi-sentence, but not in a sugi-sentence? I do not have a good answer for this question, but here is an interesting observation. The structures in (50) and (22) are related to the two readings which do not have the same status. (22), where the FNQ scopes above -sugi, is related to the salient reading. (53), 
The ingredients of comparison

where the FNQ scopes below -sugi, is related to the non-salient reading. The structure in (56) is similar to (50) in that it has the FNQ below sugi. This seems to suggest that the structures with the FNQ below -sugi are more marked than the one with the FNQ above sugi. However, it is unclear what underlies such a distinction.

\section{References}

Aihara, Masahiko. 2009. The scope of -est: evidence from Japanese. Natural Language Semantics 17(4). 341-367. http://dx.doi.org/10.1007/s11050oog-9046-6.

Barker, Chris. 2007. Parasitic scope. Linguistics and Philosophy 30(4). 407444. http://dx.doi.org/10.1007/s10988-007-9021-y.

Bartsch, Renate \& Theo Vennemann. 1972. Semantic structures: A study in the relation between syntax and semantics. Frankfurt: Athenaüm Verlag.

Beck, Sigrid, Toshiko Oda \& Koji Sugisaki. 2004. Parametric variation in the semantics of comparison: Japanese vs. English. Journal of East Asian Linguistics 13(4). 289-244. http://dx.doi.org/10.1007/s10831-004-1289-o.

Bhatt, Rajesh \& Shoichi Takahashi. 2011. Reduced and unreduced phrasal comparatives. Natural Language and Linguistic Theory 29(3). 581-620. http://dx.doi.org/10.1007/s11049-011-9137-1.

Doetjes, Jenny. 1997. Quantifiers and selection. On the distribution of quantifying expressions in French, Dutch and English. Leiden University PhD thesis. https://openaccess.leidenuniv.nl/handle/1887/19731.

Fraassen, Bas van. 1969. Presupposition, supervaluations, and free logic. In Karel Lambert (ed.), The logical way of doing things, 67-91. New Haven, CT: Yale University Press.

Fujita, Naoya. 1994. On the nature of modification: A study of floating quantifiers and related constructions. Rochester, NY: University of Rochester PhD thesis.

Fukushima, Kazuhiko. 1991. Generalized floating quantifiers. Tucson, AZ: University of Arizona $\mathrm{PhD}$ thesis.

Heim, Irene. 2000. Degree operators and scope. Semantics and Linguistic Theory (SALT) 10. 40-64. http://elanguage.net/journals/salt/article/ view/10.40.

Heim, Irene \& Angelika Kratzer. 1998. Semantics in generative grammar. Malden, MA: Blackwell. 
Hoeksema, Jack. 1983. Negative polarity and the comparative. Natural Language and Linguistic Theory 1(3). 403-434. http://dx.doi.org/10.1007/ BFoo142472.

Ishii, Yasuo. 1998. Floating quantifiers in Japanese: NP quantifiers, VP quantifiers, or both? In Researching and verifying on advanced theory of human language, Grant-in-Aid for COE research report, vol. 2, 149-171. Kanda, Japan: Kanda University of International Studies, Graduate School of Language Sciences.

Kageyama, Taro \& Yoko Yumoto. 2007. Gokeisei to gainen kozo (Word formation and conceptual structure). Tokyo: Kenkyusha.

Kamp, Hans. 1975. Two theories of adjectives. In Edward Keenan (ed.), Formal semantics of natural language, 123-155. Cambridge University Press.

Kato, Shigehiro. 1997. Nihongo-no rentaisuuryooshi-to yuurisuuryooshi-no bunseki (An analysis of pre-nominal numeral quantifiers and floating numeral quantifiers in Japanese). Toyama Daigaku Jinmongakubu Kiyoo 26. 31-64.

Kennedy, Christopher. 1997. Projecting the adjective: The syntax and semantics of gradability and comparison. University of California, Santa Cruz $\mathrm{PhD}$ thesis.

Kennedy, Christopher. 2007. Modes of comparison. Chicago Linguistic Society (CLS) 43(1). 141-165. http://cls.metapress.com/content/913k657037422361/.

Kennedy, Christopher \& Jason Stanley. 2009. What an average semantics needs. Semantics and Linguistic Theory (SALT) 18. 465-482. http://hdl. handle.net/1813/13050.

Kitagawa, Yoshihisa \& S.-Y. Kuroda. 1992. Passive in Japanese. Ms., Indiana University.

Kobuchi-Philip, Manna. 2003. Distributivity and the Japanese floating numeral quantifiers. The City University of New York PhD thesis.

Kobuchi-Philip, Manna. 2007. Individual-denoting classifiers. Natural Language Semantics 15(2). 95-130. http://dx.doi.org/10.1007/s11050-0079011-1.

Koizumi, Masatoshi. 1998. Invisible Agr in Japanese. The Linguistic Review 15(1). 1-37. http://dx.doi.org/10.1515/tlir.1998.15.1.1.

Lewis, David. 1973. Counterfactuals. Oxford: Blackwell.

Li, Xiao. 2009. Degreeless comparatives. New Brunswick, NJ: Rutgers University $\mathrm{PhD}$ thesis. 
The ingredients of comparison

Matsui, Ai \& Yusuke Kubota. 2010. Comparatives and contrastiveness: Semantics and pragmatics of Japanese Hoo comparatives. Formal approaches to Japanese linguistics (FAJL) 5 .

McConnell-Ginet, Sally. 1973. Comparative constructions in English: a syntactic and semantic analysis. Rochester, NY: University of Rochester PhD thesis.

Meier, Cécile. 2003. The meaning of too, enough, and so...that. Natural Language Semantics 11(1). 69-107. http:// dx.doi.org/10.1023/A : 1023002608785.

Miyagawa, Shigeru. 1989. Structure and case marking in Japanese. New York: Academic Press.

Nakanishi, Kimiko. 2004a. On comparative quantification in the verbal domain. Semantics and Linguistic Theory (SALT) 14. 179-196. http://elanguage. net/journals/salt/article/view/14.179.

Nakanishi, Kimiko. 2004b. Domains of measurement: Formal properties of non-split/split quantifier constructions. Philadelphia, PA: University of Pennsylvania PhD thesis.

Nakanishi, Kimiko. 2007a. Formal properties of measurement constructions. Berlin: Mouton de Gruyter.

Nakanishi, Kimiko. 2007b. Measurement in the nominal and verbal domains. Linguistics and Philosophy 30(2). 235-276. http://dx.doi.org/10.1007/ s10988-007-9016-8.

Oda, Toshiko. 2008. Degree constructions in Japanese. Storrs, CT: University of Connecticut PhD thesis.

Percus, Orin. 2000. Constraints on some other variables in syntax. Natural Language Semantics 8(3). 173-229. http://dx.doi.org/10.1023/A: 1011298526791.

Ross, John. R. 1969. A proposed rule of tree-pruning. In David A. Reibel \& Sanford A. Schane (eds.), Modern studies in English: Readings in transformational grammar, 288-299. Prentice-Hall.

Sasaki Alam, Yukiko. 1997. Numeral classifiers as adverbs of quantification. Japanese and Korean Linguistics 6. 381-397.

Sawada, Osamu \& Thomas Grano. 2011. Scale structure, coercion, and the interpretation of measure phrases in Japanese. Natural Language Semantics 19(2). 191-226. http://dx.doi.org/10.1007/s11050-011-9070-1.

Schwarzschild, Roger. 2005. Measure phrases as modifiers of adjective. Recherches linguistiques de Vincennes 34. 207-228. http://rlv.revues. org/1401. 
Schwarzschild, Roger. 2008. The semantics of comparatives and other degree constructions. Language and Linguistics Compass 2(2). 308-331. http: //dx.doi.org/10.1111/j.1749-818X.2007.00049.x.

Seuren, Pieter. 1973. The comparative. In F. Kiefer \& N. Ruwet (eds.), Generative grammar in Europe. Dordrecht: Riedel.

Seuren, Pieter. 1984. The comparative revisited. Journal of Semantics 3(1-2). 109-141. http://dx.doi.org/10.1093/jos/3.1-2.109.

Shimoyama, Junko. 2012. Reassessing crosslinguistic variation in clausal comparatives. Natural Language Semantics 20(1). 83-113. http://dx.doi. org/10.1007/s11050-011-9076-8.

Stalnaker, Robert. 1968. A theory of conditionals. In Nicholas Rescher (ed.), Studies in logical theory, 98-112. Oxford: Blackwell.

Stalnaker, Robert. 1984. Inquiry. Cambridge, MA: MIT Press.

von Stechow, Arnim. 1984. Comparing semantic theories of comparison. Journal of Semantics 3(1-2). 1-77. http://dx.doi.org/10.1093/jos/3.1-2.1.

Sugioka, Yoko. 1985. Interaction of derivational morphology and syntax in Japanese and English. New York: Garland.

Terada, Michiko. 1990. Incorporation and argument structure in Japanese. University of Massachusetts Amherst PhD thesis.

Winter, Yoad. 2005. Cross-categorial restrictions on measure phrase modification. Linguistics and Philosophy 28(2). 233-267. http://dx.doi.org/10. 1007/s10988-004-1469-4.

Xiao Li

Department of Classical, Middle Eastern, and

Asian Languages and Cultures

Queens College, CUNY

65-30 Kissena Blvd.

Queens, NY 11367

Xiao.Li@qc.cuny.edu 